\title{
VARIAÇÃo SAZONAL E ESPACIAL DA BIOMASSA FITOPLANCTÔNICA NOS ESTUÁRIOS DOS RIOS ILHETAS E MAMUCABA (TAMANDARÉ-PE) RELACIONADA COM PARÂMETROS HIDROLÓGICOS.
}

\author{
ANA PAULA DE MiRANDA LosadA ${ }^{1,2}$ \\ FERNANDO ANTÔNIO DO NASCIMENTO FEITOSA ${ }^{1}$ \\ IARA CORREIA LINS ${ }^{1}$ \\ 1-Departamento de Oceanografia da UFPE \\ 2 - Aluna do Mestrado em Oceanografia, bolsista do CNPq
}

\begin{abstract}
RESUMO
A zona estuarina dos rios Ilhetas e Mamucaba está situada nas coordenadas de $8^{\circ} 46^{\prime} 45^{\prime \prime}$ 'S e 3506'26' 'W, no município de Tamandaré, distante 110Km do Recife. Os referidos estuários são de pequeno porte e pouco profundos, e juntamente com a vegetação de mangue formam um belo ecossistema costeiro. Com o intuito de conhecer melhor a hidrologia local e a ecologia da comunidade fitoplanctônica é que foi realizada esta pesquisa, tendo como objetivo maior determinar a biomassa fitoplanctônica relacionando-a com parâmetros hidrológicos, considerando sua variação sazonal e espacial. Foram feitas coletas mensais de fevereiro de 1998 a janeiro de 1999, em quatro estações fixas, na preamar e na baixa-mar de um mesmo dia e na superfície. As amostras para biomassa foram coletadas com garrafas plásticas e as abióticas com uma de garrafa de Nansen. Para a clorofila $\boldsymbol{a}$ utilizou-se o método espectrofotométrico, também foram determinados os seguintes parâmetros hidrológicos: nitrito, nitrato, fosfato, silicato, oxigênio dissolvido, DBO, pH, salinidade, temperatura, transparência e material em suspensão. A biomassa fitoplanctônica variou desde valores indetectáveis até $22,20 \mathrm{mg} \cdot \mathrm{m}^{-3}$ apresentando uma certa variação espacial e sazonal, apenas nas estações 3 e 4 na baixa-mar, estando mais elevada no período de estiagem. Observou-se, também, que a biomassa mostrou uma relação direta com o silicato e com a salinidade, porém com esta última apenas nas estações 1 e 2 , e inversa com a pluviometria. De acordo com os teores de xigênio dissolvido e a demanda bioquímica do oxigênio o ambiente estudado mostrou-se característico de uma área despoluída.
\end{abstract}

Palavras-chave: fitoplâncton, biomassa, estuário, hidrologia.

\begin{abstract}
The estuarine zone of Ilhetas and Mamucaba rivers is located at $8^{\circ} 46^{\prime} 45^{\prime \prime} \mathrm{S}$ and 3506'26' W, near Tamandaré Town, $110 \mathrm{~km}$ south of Recife. These estuaries are short and shallow, and together with the mangrove vegetation form a beautiful coastal ecosystem. In order to know the hidrology and phytoplankton community it was designed this project to assess the phytoplankton biomass and its correlation with some hydrological parameters, considering the seasonal and spatial variations. Collections were carried out monthly, from February/1998 to January/1999, at surface, in 4 fixed stations, during low and high tides. Phytoplankton biomass samples were collected with a plastic bottle and the abiotic parameters (salinity, $\mathrm{pH}$, dissolved oxigen, Biochemical Oxigen Demand and nutrients salts) with a Nansen bottle. Water temperature and transparency (Secchi Disk) were measured in situ. The chlorophyll $a$ was measured by the spectrophotometric method. Phytoplankton biomass varied from non detectable values to 22,20mg. $\mathrm{m}^{-3}$ and showed seasonal and spatial variations at stations 3 and 4 (upstream) at low tide,
\end{abstract}

Tropical Oceanography, Recife: v. 31, n. 1, p. 1-26, 2003 
being higher at dry season. The phytoplankton biomass showed a direct correlation with silicate and salinity, however with the last one only at stations 1 and 2, and inverse correlation to rainfall at stations 3 and 4. The high oxygen saturation and low Biochemical Oxigen Demand revealed a non polluted area.

Key-words: Phytoplankton, biomass, estuary, hidrology.

\section{INTRODUÇÃO}

Conforme a definição de Pritchard (1967), estuário é um corpo de água costeira semifechado com uma conexão livre com o mar aberto e dentro do qual a água marinha é diluída com a água doce proveniente da drenagem terrestre.

São áreas frequentemente mais produtivas do que quaisquer das massas d’água salgada e doce que lhes são contínuas, talvez devido à ' armadilha alimentar' formada pela mistura de águas de diferentes salinidade e a ação favorável das correntes de maré, de caráter oscilante, no que se refere ao transporte de nutrientes alimentos e resíduos (ODUM, 1959).

Há um bom tempo os estuários e áreas costeiras vêm sofrendo impactos diversos, tais como aterro, degradação e poluição, levando, dessa maneira, a uma gradativa diminuição de biodiversidade, fazendo com que haja uma redução na oferta de seus recursos alimentares. Esses impactos muitas vezes levam a graves consequências, não só para as espécies que aí habitam mas para o próprio ser humano.

A preservação desses ambientes é de vital importância, pois, além de servirem como local de alimentação, criação, habiat, refúgio e reprodução de diversas espécies de importância econômica e ecológica, são grandes produtores de alimento para o homem, quando muitas famílias retiram seu sustento desses ecossistemas.

Possuem uma vegetação típica e uma variedade de organismos produtores de matéria orgânica aumentando, assim, a disponibilidade de alimentos para os demais elos da teia trófica. Dentre os produtores primários destaca-se a comunidade fitoplanctônica. Essa comunidade apresenta variações diurnas em sua composição específica, sua biomassa, sua densidade e na produtividade, provocadas pelo fluxo e refluxo das marés. As variações sazonais também são comuns nessa comunidade, e em regiões tropicais a amplitude e periodicidade dessas variações dependem quase que exclusivamente do regime de chuvas. Diferenças sazonais nas descargas dos rios provocam alterações nos valores de salinidade e nas condições quali-quantitativas do fitoplâncton (SOURNIA, 1969).

Os estuários dos rios Ilhetas e Mamucaba são ainda exemplos de ambientes pouco impactados pela ação antrópica o que torna de grande importância seu conhecimento e a sua preservação. Com o intuito de se conhecer a variação sazonal e espacial da biomassa fitoplanctônica, em diferentes regimes de maré, e a sua relação com os parâmetros hidrológicos é que se desenvolveu este trabalho, sendo ele pioneiro para o referido sistema costeiro.

\section{DESCRIÇÃo DA ÁREA}

O município de Tamandaré encontra-se distante da cidade do Recife cerca de $110 \mathrm{Km}$. Possui um clima do tipo AS' denominado Tropical Quente Úmido, com chuva de outono-inverno, caracterizando-se por apresentar dois períodos distintos no regime pluviométrico: uma estação chuvosa, de março a agosto, e uma seca, de setembro a fevereiro. Apresenta um pequeno centro comercial e uma agroindústria do açúcar e do álcool, predominando a monocultura da cana-deaçúcar.

Tropical Oceanography, Recife: v. 31, n. 1, p. 1-26, 2003 
Uma outra atividade desenvolvida nesta área é a da pesca artesanal realizada nos estuários, próxima aos recifes e até a distância máxima de 27 milhas da costa, tendo como produto final peixes, crustáceos (camarão e caranguejo) e moluscos (polvos e bivalves) (BOTELHO et al., 1999).

Os rios Ilhetas e Mamucaba são rios de terceira ordem, ou seja, são pequenos, pouco volumosos e estreitos, na maioria do seu percurso. Possuem uma profundidade média em sua área estuarina de $1,50 \mathrm{~m}$ durante a preamar. O primeiro nasce no município de Barreiros e possui aproximadamente $8 \mathrm{Km}$ de extensão, e o segundo nasce na reserva Biológica de Saltinho, no município de Rio Formoso, apresentando cerca de 5Km de extensão, e ambos deságuam juntos no Oceano Atlântico. Possuem em suas margens uma densa vegetação de mangue do tipo riberinho representada por Rhizophora mangle Linnaeus (mangue vermelho), Laguncularia racemosa Gaerth (mangue branco), Avicennia schaueriana Stapf \& Leichman (canoé) e Conocarpus erectus Linnaeus (mangue-de-botão) e uma rica fauna de moluscos e crustáceos associados a essa vegetação. De acordo com Galvão (1996) a comunidade microzooplanctônica, presente nessa área, está representada por 10 espécies distribuídas em 4 gêneros e 1 classe, Polyhymenophora, já o microfitoplâncton está representado por 90 espécies distribuídas em 48 gêneros e 5 classes, dentre as quais destaca-se a classe Bacillariophyceae como a mais dominante.

Fatos importantes a mencionar são que eles estão sujeitos a quase nenhuma ação antrópica e encontram-se inseridos na Área de Proteção Ambiental (APA-Costa dos Corais), criada recentemente pelo Governo Federal em 1997, que ocupa 120Km de extensão e 34Km de largura e abrange dez municípios do litoral dos Estados de Pernambuco e Alagoas.

\section{MATERiAL e MÉtodos}

As estações de coleta foram delimitadas baseadas na heterogeneidade espacial, ficando

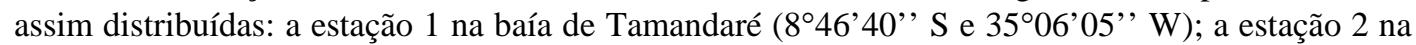

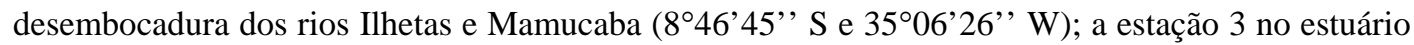
do rio Ilhetas ( $8^{\circ} 47^{\prime} 13^{\prime}$ ' S e 3506'18', W) e a estação 4 no estuário do rio Mamucaba (8 46’24', S e $35^{\circ} 06^{\prime} 30^{\prime \prime}$ W) (Fig. 1).

As amostras de água foram coletadas mensalmente, na superfície, no período de fevereiro/98 a janeiro/99, em quatro estações fixas, durante a preamar e a baixa-mar de um mesmo dia.

As amostras para a determinação da biomassa fitoplanctônica, foram coletadas com garrafas plásticas de um litro e foram filtradas no laboratório do CEPENE. Para a filtração, à vácuo, usou-se membranas filtrantes Schleicher \& Schull de $47 \mathrm{~mm}$ de diâmetro e 0,45 $\mu \mathrm{m}$ de porosidade, e foram filtrados volumes variando de 0,15 a 0,50 litros. A análise foi feita através do método espectrofotométrico de Parsons \& Strickland (1963), detalhadamente descrito em Unesco (1966) e Teixeira (1973).

As amostras para os parâmetros hidrológicos foram obtidas com garrafas plásticas, exceto as amostras de oxigênio dissolvido e DBO que foram coletadas por intermédio de uma garrafa de Nansen. As análises de oxigênio dissolvido, DBO, nutrientes e material em suspensão foram feitas no laboratório de Oceanografia Química do Departamento de Oceanografia da UFPE. Os demais parâmetros foram determinados em campo. A profundidade local foi medida através de uma ecossonda manual digital Echotest da Plastimo; a transparência da água por intermédio de um disco de Secchi; a temperatura da água através de um termômetro comum de mercúrio com escala entre $10^{\circ} \mathrm{C}$ e $60^{\circ} \mathrm{C}$; a salinidade através de um refratômetro manual da Atago; o potencial hidrogeniônico, por intermédio de um pH-metro Beckman Zeromatic II; o oxigênio dissolvido foi analisado pelo método de Winkler descrito por Strickland \& Parsons (1972); a demanda bioquímica do oxigênio pelo método descrito no Standard Methods for Examination of Water and Waste Water (APHA, 1985); os sais nutrientes (nitrito, nitrato e fosfato) através do método de Strickland \& Parsons (op.

Tropical Oceanography, Recife: v. 31, n. 1, p. 1-26, 2003 
cit.) e o silicato pelo método de Grasshoff et al..(1983) e o material em suspensão pelo método de Mello et al. (1975).

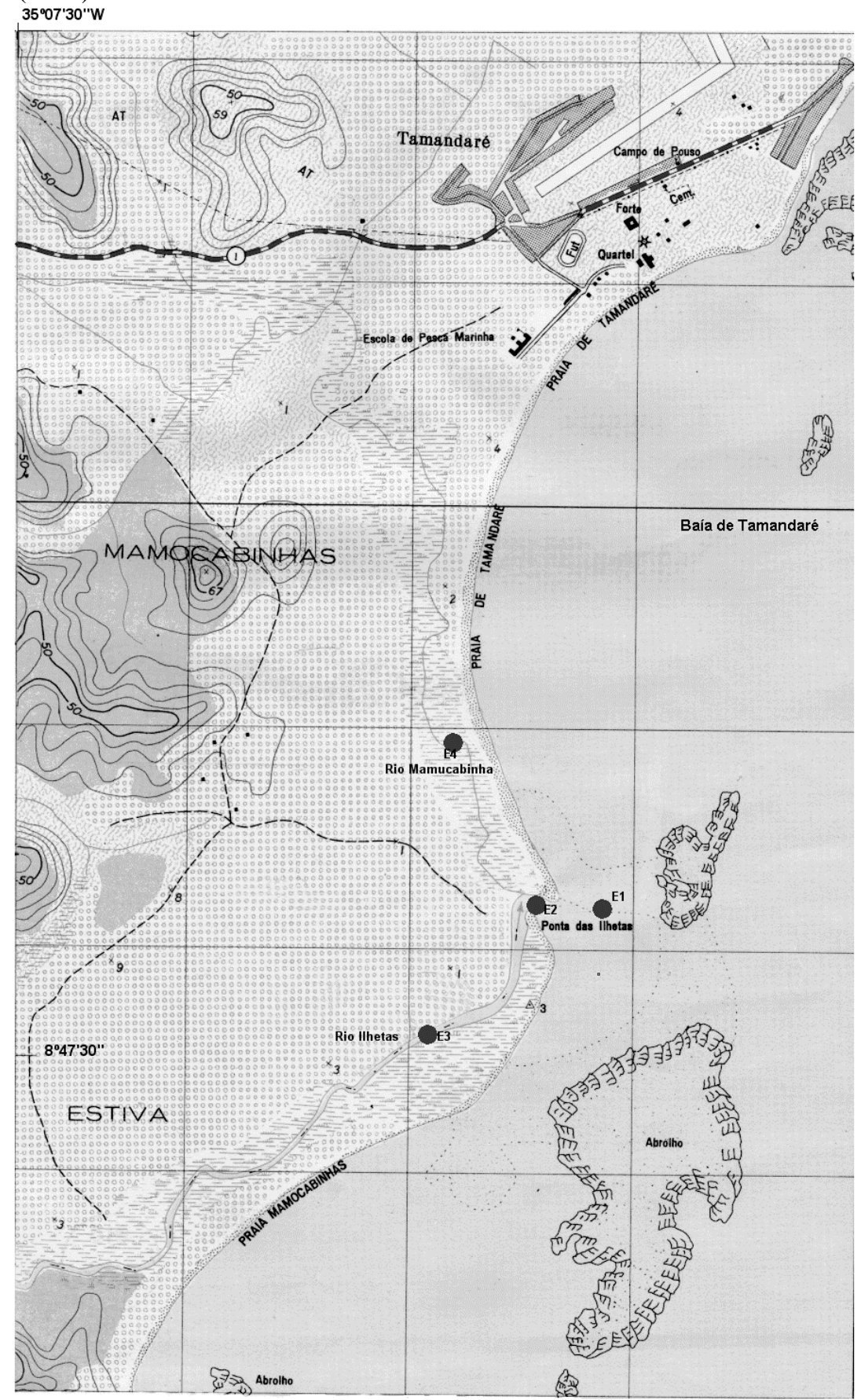

Fonte: Sudene (1972) esc.1:25.000

Figura 1 - Área estudada com as estações de coleta

Tropical Oceanography, Recife: v. 31, n. 1, p. 1-26, 2003 


\section{RESUlTADOS E DiscuSSÃo}

O ecossistema estuarino é muito importante para a comunidade biológica costeira em geral, por se tratar de uma área naturalmente enriquecida, proporcionando habitat, abrigo, alimento a uma gama de organismos marinhos, estuarinos e limnéticos. Devido a sua localização ele sofre a ação das marés apresentando, portanto, um forte grau de hidrodinamismo, o qual interfere nas condições físico-químicas e biológicas que variam bastante num curto espaço de tempo.

Neste sentido, a profundidade local passa a ser um fator importante em relação a mistura da água, uma vez que, o ambiente sendo pouco profundo permite uma maior homogeneização da coluna d'água e ressuspensão do sedimento e dos nutrientes retidos nele.

De uma maneira geral, a profundidade da área estudada apresentou-se muito pequena, à exceção apenas da estação 1, localizada na Baía de Tamandaré. A profundidade local variou de $0,30 \mathrm{~m}$ registrado na estação 4 , no mês de fevereiro/98, na baixa-mar até $8,00 \mathrm{~m}$ obtido na estação 1 , em agosto e dezembro/98, durante a preamar (Tab. 1 a 8).

A transparência da água nos estuários apresentou-se geralmente total ao longo do período estudado, ou seja, a profundidade de desaparecimento do disco de Secchi coincidiu com a profundidade local, com exceção em agosto, setembro e dezembro/98, na estação 2 e em maio/98, na estação 3, na preamar e em maio e agosto/98, nas estações 2, 3 e 4, na baixa-mar. A estação 1 mostrou um decréscimo de maio a agosto/98 (Tab. 1 a 8). O valor mínimo encontrado foi de 0,20m, na estação 3, em agosto/98, na baixa-mar, enquanto a máxima obtida foi de 4,70m na estação 1 , em setembro/98, na preamar (Tab. 1 a 8). Do ponto de vista espacial ela tendeu a diminuir da baía (estação 1) para o interior dos estuários (estações 3 e 4). Estes valores estão compatíveis com os encontrados em outros estuários da região por Oliveira (1985) no estuário do rio Potengi (RN), por Feitosa (1988) no estuário da Bacia do Pina(PE) e por Santos-Fernandes (1997) no estuário do rio Jaguaribe(PE).

Como a transparência da água é uma função da chuva e da drenagem terrestre, pode-se esperar que a luz seja limitante para o fitoplâncton nos meses de maior pluviometria, podendo limitar a produção potencial da biomassa fitoplanctônica. A luz é considerada como um dos fatores mais limitantes para a produção primária (PASSAVANTE e KOENING,1984; SASSI,1991; MOREIRA,1994). No ambiente estudado, acredita-se que a luz não interferiu de forma significativa na quantidade do pigmento fotossintético, uma vez que não se observou uma relação da transparência da água com a clorofila $\boldsymbol{a}$. Já Koening (1997), estudando o estuário do rio Ipojuca (PE), constatou que os altos valores de clorofila a coincidiram com aumento da turbidez da água e baixa intensidade luminosa.

Em maio e agosto/98 a coloração da água dos estuários apresentou uma cor marrom escuro, não se tratando de um 'bloom”' de fitoplâncton. De acordo com Reid (1961), detritos suspensos e organismos vivos contribuem para que a coloração da água varie do marrom ao verde. E que materiais dissolvidos tais como o ácido tanínico, liberado pelo influxo do rio ou de decomposição local de substratos orgânicos, contribuem para tornar o estuário marrom.

O material em suspensão não apresentou grandes concentrações, possivelmente pelo fato de 1998 e 1999 terem tido uma média pluviométrica (917,7 e 917,2mm, respectivamente) abaixo da média histórica para o período de 1991 a 1999 (1.632,43mm). Koening (op. cit.) também verificou baixos valores de material em suspensão para o estuário do rio Ipojuca (PE), associando este fato à baixa precipitação pluviométrica em 1990. Houve uma diferença significativa entre as marés, tendo a baixa-mar apresentado as maiores concentrações, o que evidencia a contribuição dos rios para o aporte de material em suspensão no ecossistema estudado. Uma outra observação feita é que no período chuvoso encontrou-se os maiores teores de material em suspensão. $\mathrm{O}$ valor mínimo encontrado foi de $1,4 \mathrm{mg} . \mathrm{L}^{-1}$, na estação 1 , em outubro/98, na baixa-mar e o máximo foi de 56,0 mg.L ${ }^{-1}$, na estação 3, em maio/98, na baixa-mar (Fig. 2 e Tab. 1 a 8). Lira et al. (1978), trabalhando no rio Mamucaba, encontroram teores bem maiores de material em suspensão em relação aos

Tropical Oceanography, Recife: v. 31, n. 1, p. 1-26, 2003 
obtidos neste trabalho e relatam que houve uma relação direta da concentração de material em suspensão com a salinidade, ao contrário do que foi aqui registrado.

A temperatura da água acompanhou a do ar, apresentando uma discreta variação sazonal, com os menores valores no período chuvoso. A mínima encontrada foi de $26^{\circ} \mathrm{C}$ nas estações 2 , 3 e 4 em julho, agosto e setembro/98 tanto na preamar como na baixa-mar enquanto a máxima foi de $32^{\circ} \mathrm{C}$ obtidos nas estações 2 , 3 e 4 em fevereiro/98, durante a baixa-mar (Tab. 1 a 8).

Com relação à salinidade o menor valor registrado, na área estudada, foi de $0 \%$, encontrado na estação 3, em maio e agosto/98, na baixa-mar e na estação 4, em maio, agosto e setembro/98 também na baixa-mar. O maior valor registrado foi de 36\%, na estação 1, em fevereiro e março/98, na baixa-mar (Fig. 3 e Tab. 1 a 8). Lira et al (1978) também encontraram para o rio Mamucaba uma salinidade mínima de $0 \%$.

Não houve durante a preamar, com exceção de alguns meses, uma diferença espacial nítida, mostrando o ambiente uma mesma massa d'água durante esta maré. Já na baixa-mar observou-se um gradiente decrescente, bem acentuado, da baía para os estuários, que apresentaram, por sua vez, valores bem mais baixos que na preamar. Foi observado um padrão sazonal para a salinidade, ocorrendo um decréscimo dos valores no período chuvoso (Fig. 3 e Tab. 1 a 8).

Lira et al (op. cit.) comentam que a grande variabilidade salina existente no Mamucaba está relacionada à grande diluição das águas exercida pelo rio na baixa-mar. O mesmo pode ser dito para o Ilhetas.

Os estuários dos rios Ilhetas e Mamucaba apresentaram um padrão salino variando do limnético ao eualino, o que, segundo Feitosa (1997), é normal para áreas estuarinas.

Vários autores têm comentado sobre a influência da salinidade da água sobre o crescimento, desenvolvimento, biomassa, distribuição e fisiologia do fitoplâncton (REBELLO e BRANDINI,1990; BERGESCH e ODEBRECHT, 1997; FEITOSA, op. cit.). Rebello e Brandini (op. cit.), trabalhando na baía de Paranaguá (PR), verificaram a existência de uma correlação inversa entre a salinidade e as concentrações de clorofila $\boldsymbol{a}$. Na atual pesquisa, as maiores concentrações de clorofila $\boldsymbol{a}$ foram encontradas em baixas salinidades.

$\mathrm{O}$ ambiente estudado apresentou valores alcalinos de $\mathrm{pH}$ ao longo do ano, com exceção da estação 2, em agosto/98, na preamar e das estações 3 e 4, em maio/98, na baixa-mar, cujos valores, respectivamente, foram 6,$8 ; 6,9$ e 6,9. O maior valor obtido, 8,6, foi registrado na estação 1 , em fevereiro/98, na preamar (Tab. 1 a 8). Vale ressaltar que os valores acima citados estão dentro dos limites aceitáveis para a vida marinha que varia de 6,5 a 9,0, segundo Perkins (1977). Normalmente, o pH nos estuários e baías mantém-se geralmente alcalinos, podendo apresentar, também, valores ácidos e neutro que, segundo Horne (1978) apud Costa e Macedo (1987/89), deve-se à produção de ácido sulfídrico.

Percebeu-se uma certa variação espacial, ocorrendo um gradiente decrescente da estação 1 para as estações 3 e 4, principalmente na baixa-mar. Também foi observado na baixa-mar um decréscimo do $\mathrm{pH}$, nos estuários, no período chuvoso. Outros autores como, Resurreição et al. (1996), Establier et al. (1987) e Fernandes (1997) relatam, para os ambientes em que trabalharam, uma diminuição do $\mathrm{pH}$ no período invernal.

O teor de oxigênio dissolvido na água, que é um excelente parâmetro indicador da qualidade ambiental, não demonstrou sazonalidade definida no período estudado, mas sim redução dos valores em alguns meses do período chuvoso e outros do período seco. Os valores de oxigênio variaram entre $0,42 \mathrm{ml} \cdot \mathrm{L}^{-1}$, correspondendo a $7,66 \%$ de saturação, na estação 3 , na baixa-mar e $5,65 \mathrm{ml} . \mathrm{L}^{-1}$, correspondendo a $129,00 \%$ de saturação, presente na estação 1, na baixa-mar (Fig. 4 e Tab. 1 a 8). Em relação à altura da maré verificou-se que as concentrações do oxigênio dissolvido estiveram mais elevadas durante a preamar, com exceção da estação 1 que apresentou, na maioria dos meses estudados, seus maiores valores na baixa-mar, ocorrendo, geralmente, um decréscimo da baía para os estuários. Em maio/98 foram registrados os menores teores de oxigênio dissolvido nas estações 2, 3 e 4 e em agosto/98 nas estações 2 e 3, na baixa-mar, coincidindo com a forte mudança

Tropical Oceanography, Recife: v. 31, n. 1, p. 1-26, 2003 
na coloração da água (cor de vinho a marrom). Esses mais baixos valores do oxigênio dissolvido ocorreram quando também houve uma maior concentração de material em suspensão e baixos valores de salinidade.

Eskinazi-Leça et al. (1984) e Costa e Macedo (1987/1989) relacionam valores baixos de oxigênio dissolvido e saturação a um maior consumo, decorrente da oxidação da matéria orgânica, pelas bactérias e aos intensos processos biológicos e químicos. E de acordo com Cavalcanti et al. (1981) e Travassos (1991), a fotossíntese, as trocas gasosas existentes entre a água e a atmosfera, a respiração, a decomposição aeróbica da matéria orgânica, a temperatura e a salinidade são fatores que estão estreitamente relacionados ao teor de oxigênio no ambiente aquático.

Macedo e Costa (1978) sentindo a necessidade de um sistema de classificação para as águas estuarinas do Nordeste do Brasil elaboraram o seguinte esquema baseado no teor de saturação do oxigênio: Zona saturada - com teores de saturação acima de $100 \%$; Zona de baixa saturação com teores de saturação entre 50 e 100\%; Zona semi-poluída - com teores de saturação entre 25 e 50\%; Zona poluída - com teores de saturação abaixo de 25\%.

Levando-se em consideração o sistema de classificação supracitado pôde-se observar que, durante a preamar, a área estudada apresentou-se, na maior parte do período estudado, como Zona Saturada e de Baixa Saturação, enquanto na baixa-mar, em maio e agosto/98, à exceção da estação 1, as demais estações demonstraram taxas de saturação consideradas como Zonas Semi-Poluída e Poluída (Tab. 1 a 8). No entanto, essa condição está relacionada aos processos característicos do ambiente e não ao recebimento de cargas poluidoras.

Com relação a DBO, que também é um excelente parâmetro hidrológico indicador das condições ambientais, seus valores não apresentaram uma sazonalidade, mas sim picos nos períodos de estiagem e chuvoso, e permaneceram abaixo de 3,0mg.L ${ }^{-1}$ (Fig. 5). Segundo Streeter apud OttoniNeto (1976), os valores de DBO acima de 7,00mg.L.-1 são indicativos de poluição.

Os nutrientes apresentaram uma ligeira variação espacial, porém oscilando quanto à concentração dos valores que ora foi maior na baía ora nas estações estuarinas. Para o fosfato, foi observado um aumento dos valores no período de estiagem, ao contrário do que ocorreu para o nitrito, cujos maiores valores concentraram-se no período chuvoso. O nitrato apresentou seus maiores valores de fevereiro a setembro/98, coincidindo mais com o período chuvoso. Com relação às marés, a estação 1 apresentou concentrações maiores de nitrato na preamar e a estação 3 na baixa-mar. Já o nitrito e o fosfato não apresentaram muita diferença entre as marés. Os valores para o fosfato variaram de indetectável a $0,31 \mu \mathrm{mol} . \mathrm{L}^{-1}$, o nitrito variou de indetectável a $0,99 \mu \mathrm{mol} . \mathrm{L}^{-1} \mathrm{e}$ o nitrato também variou de indetectável a 3,74 $\mu$ mol.L ${ }^{-1}$ (Fig. 6 a 8 e Tab. 1 a 8).

Flores-Montes et al. (1998) trabalhando no Canal de Santa Cruz (PE) e Moura (1991) na baía de Tamandaré também observaram valores mais elevados do nitrato no período chuvoso e do fosfato no período de estiagem.

O silicato foi o nutriente que mostrou uma maior variação entre os valores da preamar e da baixa-mar, encontrando-se nesta última concentrações mais elevadas. Também nota-se que, na maioria dos meses, o silicato apresentou-se mais elevado nos estuários. Quanto a um padrão sazonal as estações 2, 3 e 4 obtiveram seus maiores valores no período seco, entretanto, esta observação é verificada apenas na baixa-mar, com relação à estação 1 esta teve comportamento inverso, encontrando-se valores mais elevados no período chuvoso em ambas as marés, mostrando uma distinção entre a região estuarina e a costeira. O menor valor registrado para o silicato foi de 3,21 $\mu$ mol.L $L^{-1}$ e o maior foi de $118,80 \mu$ mol.L ${ }^{-1}$ (Fig. 9 e Tab. 1 a 8 ).

Em estudo feito no estuário do rio Congo (PE), Fernandes (1997) constatou uma variação sazonal nos teores do silicato, com os maiores valores no período de estiagem, corroborando com as observações feitas para a área estuarina do Ilhetas e Mamucaba, na baixa-mar.

No que se refere ao comportamento da biomassa fitoplanctônica na área estudada, observou-se que ela variou desde valor indetectável $\left(0,00 \mathrm{mg} \cdot \mathrm{m}^{-3}\right)$ registrado na estação 1 , em janeiro/99, na preamar, até 22,20 mg.m ${ }^{-3}$, na estação 3, em novembro/98, na baixa-mar (Fig. 10),

Tropical Oceanography, Recife: v. 31, n. 1, p. 1-26, 2003 
demonstrando esses valores, que o ambiente estudado, caracteriza-se como uma área com baixa ação antrópica.

Os valores de clorofila $\boldsymbol{a}$ ora foram maiores numa estação ora em outra. Pôde-se perceber que as estações 1 e 2 apresentaram concentrações de clorofila $\boldsymbol{a}$ mais elevadas durante a preamar, enquanto as estações 3 e 4 na baixa-mar. Observou-se também, que a biomassa fitoplanctônica demonstrou uma relação direta com a salinidade nas estações 1 e 2 e inversa com as estações estuarinas (3 e 4). No tocante aos sais nutrientes, os teores de clorofila $\boldsymbol{a}$ apresentaram uma relação direta com o silicato. Embora, estatisticamente, não tenha ocorrido um agrupamento da clorofila $\boldsymbol{a}$ com o nitrato suas concentrações são suficientes para suprir bem a comunidade fitoplanctônica local.

Com relação à sazonalidade a biomassa fitoplanctônica apresentou-se maior no período seco, nas estações 3 e 4, na baixa-mar, No entanto na preamar não foi observado sazonalidade. Passavante (1979), trabalhando no Canal de Santa Cruz (PE), Santos-Fernandes (1997), no estuário do rio Jaguaribe (PE), e Fernandes (op. cit.), no estuário do rio Congo (PE), observaram variação sazonal dos teores de clorofila $\boldsymbol{a}$, ocorrendo maiores valores no período chuvoso, coincidindo com o aumento dos sais nutrientes, ao contrário do que foi observado por Feitosa (1988) na Bacia do Pina e por Oliveira \& Passavante (1988) no estuário do rio Potengi.

\section{REFERÊNCIAS BIBLIOGRÁFICAS}

APHA. Standard Methods for the Examination of water waste-water.16 ed. New York, 1965,1268p.

BOTELHO,E.R.O.;DIAS,A.F.;IVO,C.T.C.Estudo sobre a biologia do Caranguejo-uçá, Ucides cordatus cordatus (Linnaeus, 1763), capturado nos estuários dos rios Formoso (Rio Formoso) e Ilhetas (Tamandaré) no Estado de Pernambuco. Bol. Téc. Cient. do CEPENE, Tamandaré, v. 7, n. 1, p. 117-145, 1999.

BERGESH, M. \& ODEBRECHT, C. Análise do fitoplâncton, protozooplâncton e de alguns fatores abióticos no estuário da Lagoa dos Patos. Atlântica., Rio Grande, v. 19, p. 31-50, 1997.

CAVALCANTI, L.B.; MACEDO, S. J.; PASSAVANTE, J. Z. O. Estudo ecológico da região de Itamaracá, Pernambuco-Brasil. XXI. Caracterização do Canal de Santa Cruz em função dos parâmetros físico-químicos e pigmentos fotossintéticos. Trab Oceanogr. Univ. Fed. PE, Recife, v. 16, p. 157-216, 1981.

COSTA, K. M. P. \& MACEDO, S. J. Estudo hidrológico do rio Timbó(Pernambuco- Brasil). Trab. Oceanogr. Univ. Fed. PE, Recife, v. 20, p. 7-34, 1987/89.

ESKINAZI-LEÇA, E.; BARROS-FRANCA, L. M.; MACEDO, S. J. Estudo ecológico da área de Itamaracá (Pernambuco- Brasil). XXIV. Standing-stock do fitoplâncton do estuario do rio Botafogo, durante janeiro/dezembro/75. Trab. Oceanogr. Univ. Fed. PE, Recife, v. 18, p. 153-192, 1984.

ESTABLIER, R.;BLASCO, J.; LUBIÁN, L. M. Fitoplancton e hidrografia de la Bahía de Cádiz. Enero de 1984 a diciembre de 1985. Inv. Pesq. v. 51, n. 4, p. 501-515, dic. 1987.

FEITOSA, F. A. N. Produção primária do fitoplâncton correlacionada com parâmetros bióticos e abióticos na Bacia do Pina (Recife-PE). Recife, 1988. 279 f. Dissertação (Mestrado em Oceanografia Biológica), Departamento de Oceanografia, Universidade Federal de Pernambuco.

Tropical Oceanography, Recife: v. 31, n. 1, p. 1-26, 2003 
FEITOSA, F. A. N. Estrutura e produtividade da comunidade fitoplanctônica correlacionadas com parâmetros abióticos no sistema estuarino do rio Goiana (Pernambuco-Brasil). São Paulo, 1997, 250 f. Tese (Doutorado em Oceanografia Biológica). Instituto Oceanográfico da Universidade de São Paulo.

FERNANDES, M. A. A. Produtividade fitoplanctônica relacionada com alguns aspectos ecológicos no estuário do rio Congo (Itapissuma-Pernambuco). Recife, 1997. 146 f. Dissertação (Mestrado em Oceanografia Biológica), Departamento de Oceanografia, Universidade Federal de Pernambuco.

FLORES-MONTES, M. J.; MACEDO, S. J. de; KOENING, M. L. e CORREIA, I. L. Variação nictemeral do fitoplâncton e elementos nutrientes no Canal de Santa Cruz, Itamaracá-PE-Brasil. Trab. Oceanogr. da Univ. Fed. PE, Recife, v. 26, n. 1, p.13-26,1998.

GALVÃO, I. B. Estudo das populações microfitoplanctônicas da região sul de Tamandaré, PE, Brasil. Recife, 1996. 110 f. Monografia (Bacharelado em Ciências Biológicas), Centro de Ciências Biológicas, Universidade Federal de Pernambuco.

GRASSHOFF, K.; EHRARDT, M.; KREMLING,K. Methods of sea water analysis. 2 ed., New York, Verlag Chemie, 317, p. 1983.

KOENING, M. L. Ecologia e dinâmica do fitoplâncton no estuário do rio Ipojuca, após a implantação do Porto de Suape(PE-Brasil). Recife, 1997. 263f. Tese (Doutorado em Botânica). Universidade Federal Rural de Pernambuco.

LIRA, L.; ZAPATA, M.C.; FALCÃO, I.M. de M.; OLIVEIRA-JÚNIOR, A V. de. Material em suspensão, temperatura e salinidade no estuário do rio Mamucaba-PE. Cad. Ômega, Universidade Federal Rural de Pernambuco, Recife, v. 2, n. 1, p. 97-116, jul. 1978.

MACÊDO, S. J. \& COSTA, K. M. P. Estudo ecológico da região de Itamaracá Pernambuco- Brasil, condições hidrológicas do estuário do rio Botafogo. Ciência e Cultura, São Paulo, v. 30, n. 7, p. 368, 1978.

MELO, U.; SUMMERHAYES, C. P.; TONER, L. G. Metodologia para o estudo do material em suspensão na água do mar. Bol. Téc. Petrobrás, Rio de Janeiro, v. 18, n. 3/4, p. 115-127, 1975.

MOREIRA, M.O.P. Produção do fitoplâncton em um ecossistema estuarino tropical (Estuário do Rio Cocó, Fortaleza, Ceará). Recife, 1994. 338 f. Dissertação (Mestrado em Oceanografia Biológica), Departamento de Oceanografia, Universidade Federal de Pernambuco.

MOURA, R. T. Biomassa, produção primária do fitoplâncton e alguns fatores ambientais na Baía de Tamandaré, Rio Formoso, Pernambuco, Brasil. Recife, 1991. 290 f. Dissertação (Mestrado em Oceanografia Biológica), Departamento de Oceanografia, Universidade Federal de Pernambuco.

ODUM, E.P. Fundamentos da Ecologia. 2 ed., Lisboa, Fundação Calouste Gulbenkian, 1959. 595p.

Tropical Oceanography, Recife: v. 31, n. 1, p. 1-26, 2003 
OLIVEIRA, D. B. F. de \& PASSAVANTE, J. Z. de O . Biomassa primária do fitoplâncton do estuário do rio Potengi (Natal-Brasil). Gayana, (Bot.) v. 45, n. 1 / 4, p. 235-240, 1988.

OLIVEIRA, D. B. F. de. Produção primária do fitoplâncton do estuário do rio Potengi (NatalRN). Recife, 1985. 165 f. Dissertação (Mestrado em Oceanografia Biológica) Departamento de Oceanografia, Universidade Federal de Pernambuco.

OTTONI-NETO, T. B. Os efeitos da poluição das águas e seu controle. Secretaria Executiva do Conselho Executivo de Controle de Poluição. Aracaju. 1976. 51p.

PARSONS,T. R. \& STRICKLAND, J. D. H. Discussion of spectrophotometric determination of marine plankton pigments, with revised equations of as certaning chlorophyll $a$ and carotenoids. Journal of Marine Research, New Haven, v.21, n. 3, p. 155-163, 1963.

PASSAVANTE, J. Z. O. Produção primária do fitoplâncton do Canal de Santa Cruz (Itamaracá-PE). São Paulo, 1979. 188 f. Tese (Doutorado), Universidade de São Paulo.

PASSAVANTE, J. Z. O. \& KOENING, M. L. Estudo ecológico da região de Itamaracá(Pernambuco-Brasil).XXVI. Clorofila $\boldsymbol{a}$ e material em suspensão no estuário do rio Botafogo. Trab. Oceanogr. Univ. Fed. PE, Recife, vol. 18, p. 207-230,1984.

PERKINS, E. J. Inorganic wastes. In: LENIHAN, J. \& FLETCHER,W. W. (ed.). The Marine environments. Glasgow, Blackie \& Son Limited, 1997. p. 70-101.

PRITCHARD, D. W. What is an estuary: physical viewpoint. In: LAUFF, G. H. ED. Estuaries. Washington: American Association for the Advancement of Science, p.3-5, 1967.

REBELLO, J. \& BRANDINI, F. P. Variação temporal de parâmetros hidrográficos e material particulado em suspensão em dois pontos fixos da Baía de Paranaguá, Paraná (junho/87fevereiro/88). Nerítica. Pontal do Sul, vol., 5, n. 1, p. 95-111, jul. 1990.

REID, G. K. Ecology of inland waters and estuaries. London, Chapman \& Hall Ltd., 1961. 375p.

RESURREIÇÃO, M. G.; PASSAVANTE, J. Z. O.; MACEDO, S. J. Estudo da plataforma continental na área do Recife (Brasil): variação sazonal da biomassa fitoplanctônica (803'38', Lat. S; 3442'28', a 3452’00'’ Long. W). Trab. Oceanogr. Univ. Fed. PE, Recife, vol. 24, p. 39-59, 1996.

SANTOS-FERNANDES,T.L.Fitoplâncton do estuário do rio Jaguaribe (Itamaracá, Pernambuco, Brasil): ecologia, densidade, biomassa e produção. Recife, 1997. 175 f. Dissertação (Mestrado em Oceanografia Biológica), Departamento de Oceanografia, Universidade Federal de Pernambuco.

SASSI, R. Phytoplankton and environmental factors in the Paraíba do Norte river estuary, northeastern Brazil: composition, distribution and quantitative remarks. Bolm. Inst. Oceanogr. São Paulo, vol. 39, n.2, p. 93-115, 1991.

SOURNIA, A.Cycle annual du phytoplankton et de la production primaire dnas les mers tropicales. Marine Biology. v. 3, n.4, p.287-303, 1969. 
STRICKLAND, J. D. H. \& PARSONS, T. R. A pratical handbook of seawater analysis. 2 ed. Bulletin Fisheries Research Board of Canada, Otawa, n.167, p. 207-211, 1972.

TEIXEIRA, C. Introdução aos métodos para medir a produção primária do fitoplâncton marinho. Bol. Inst. Oceanogr. Univ. de São Paulo. São Paulo, v.22, fasc. Único, p. 59-92, 1973.

TRAVASSOS, P. E. P.F. Hidrologia e biomassa primária do fitoplâncton do estuário do rio Capibaribe, Recife-Pernambuco. Recife, 1991. 287 f. Dissertação (Mestrado em Oceanografia Biológica), Departamento de Oceanografia, Universidade Federal de Pernambuco.

UNESCO. Determination of photosynthethic pigments in sea water. Report of SCOR/UNESCO, working group 17 with meat from 4 to 6 June 1964, Paris. 1966, 69p. (Monographys on Oceanography Methodology, 1).
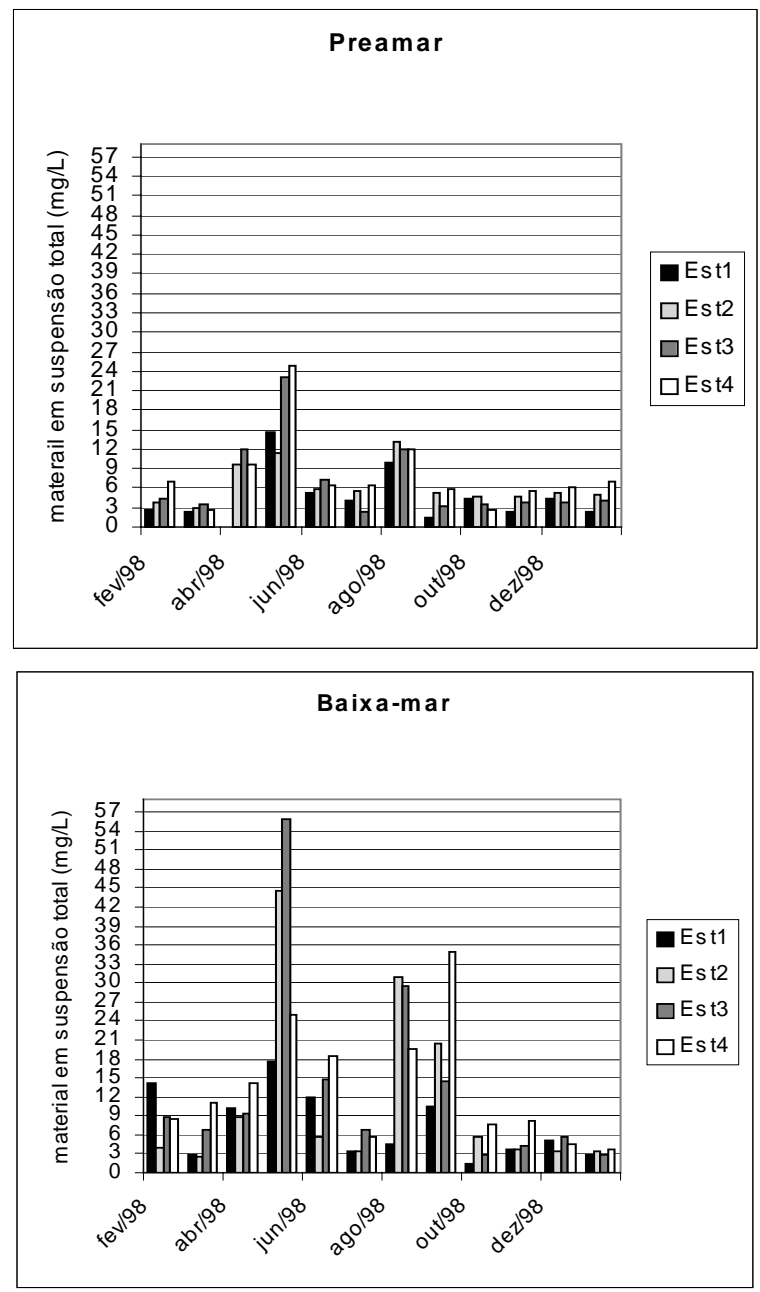

Figura 2 - Variação sazonal e espacial das concentrações do material em suspensão total nos estuários dos rios Ilhetas e Mamucaba e na Baía de Tamandaré-PE.

Tropical Oceanography, Recife: v. 31, n. 1, p. 1-26, 2003 

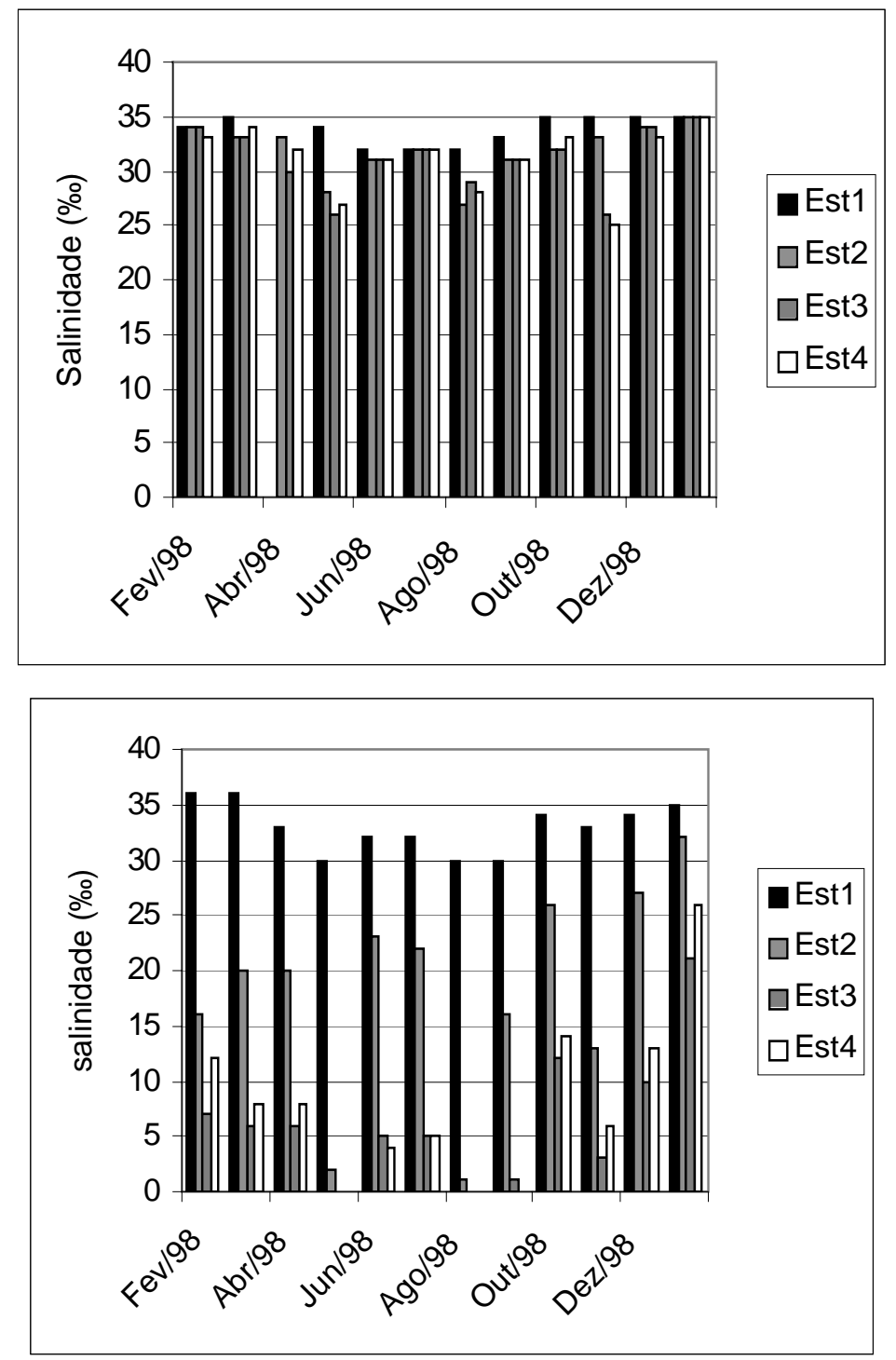

Figura 3 - Variação sazonal e espacial da salinidade nos estuários dos rios llhetas e Mamucaba e na baía de Tamandaré. 

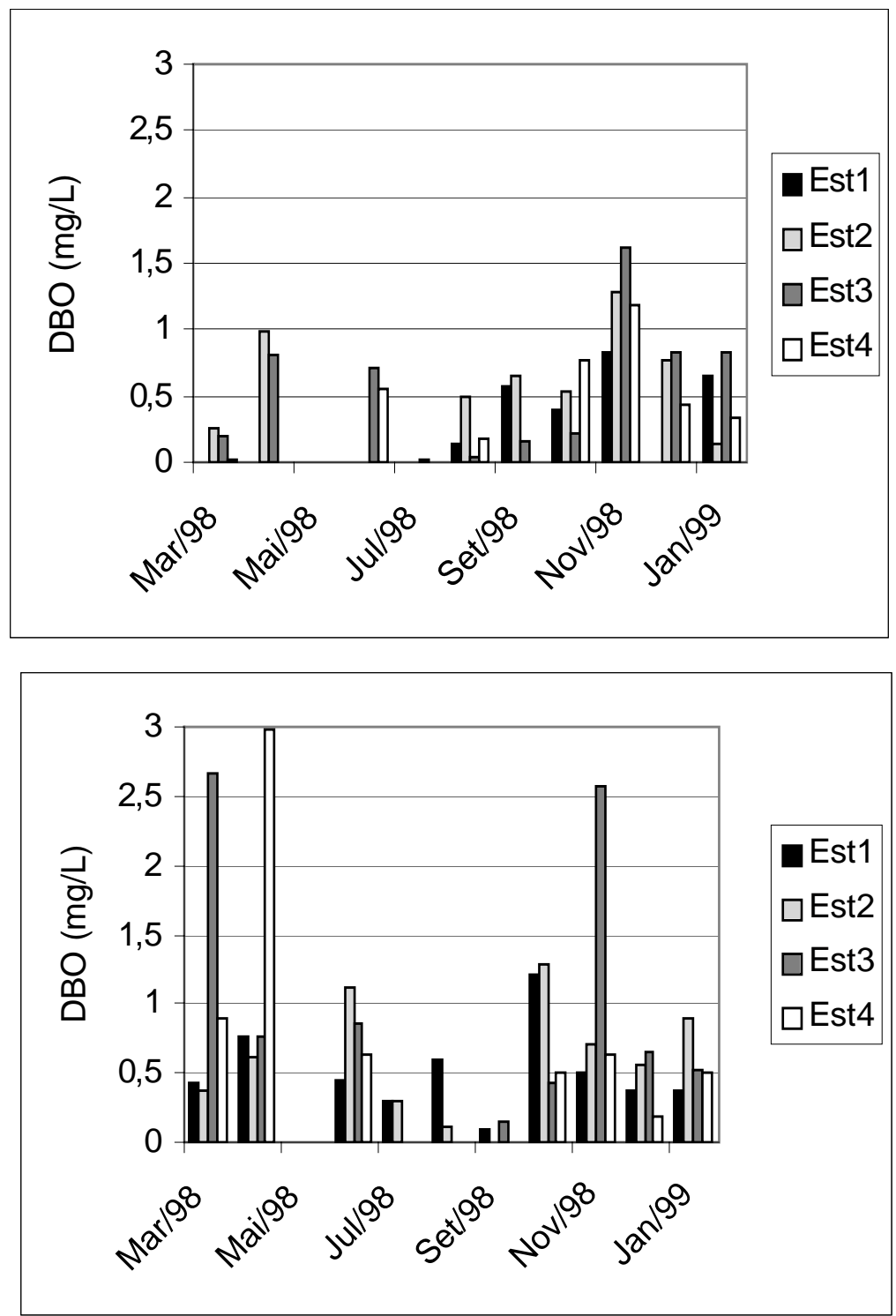

Figura 5 - Variação sazonal e espacial da DBO nos estuários dos rios Ilhetas e Mamucaba e na baía de Tamandaré 

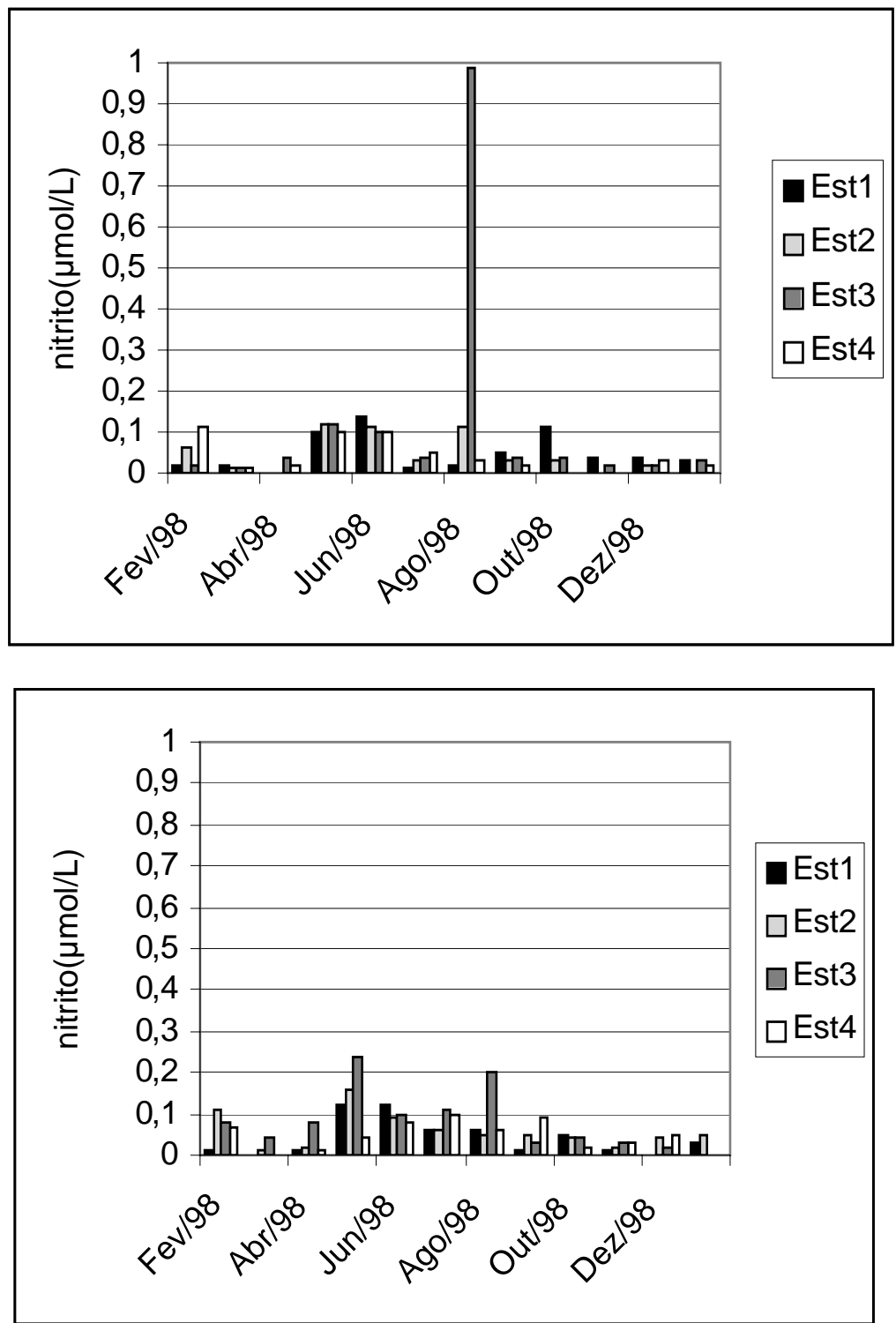

Figura 6 - Variação sazonal e espacial do nitrito nos estuários dos rios Ilhetas e Mamucaba e na baía de Tamandaré.

Tropical Oceanography, Recife: v. 31, n. 1, p. 1-26, 2003 

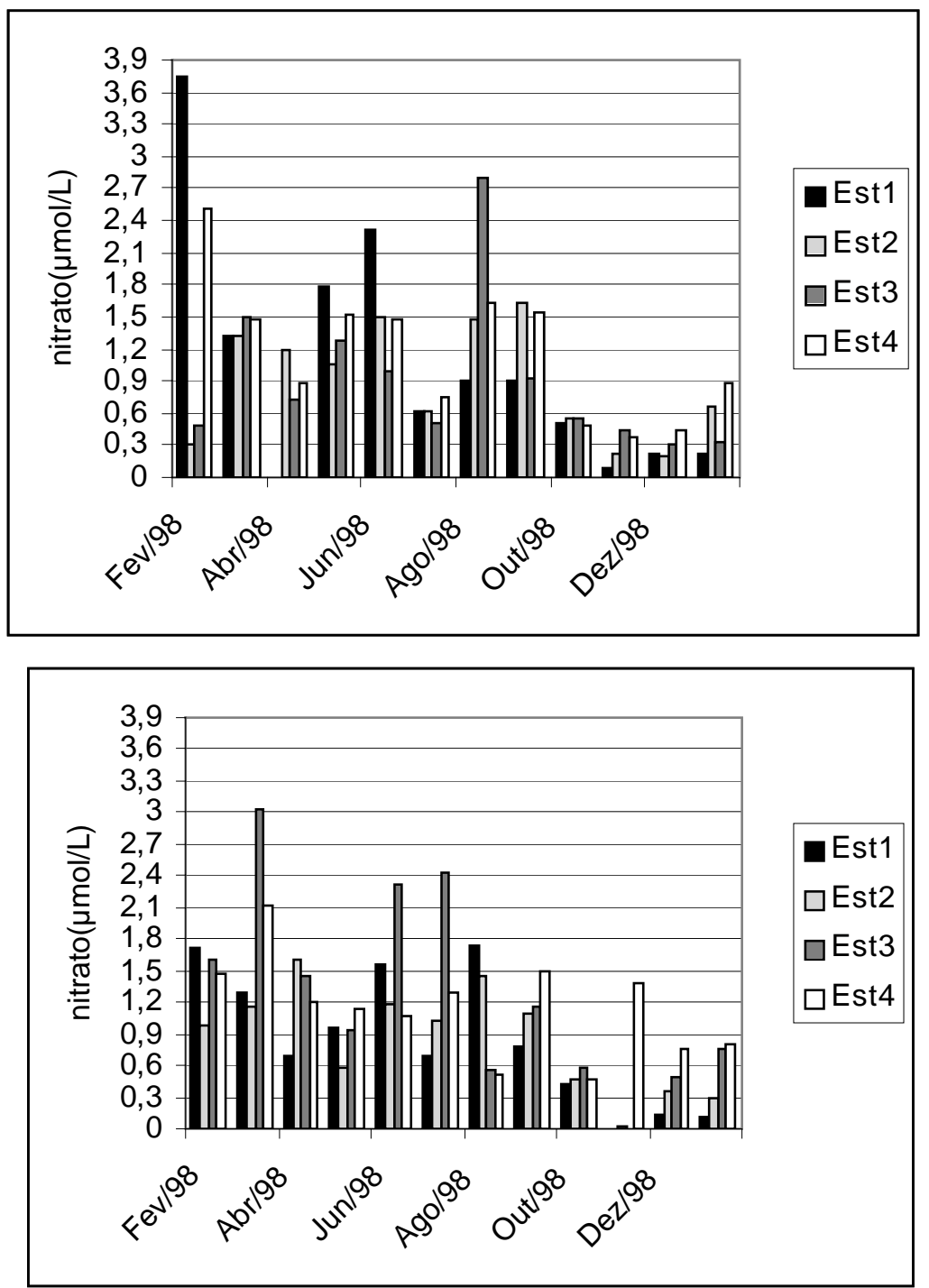

Figura 7 - Variação sazonal e espacial do nitrato nos estuários dos rios Ilhetas e Mamucaba e na baía de Tamandaré. 

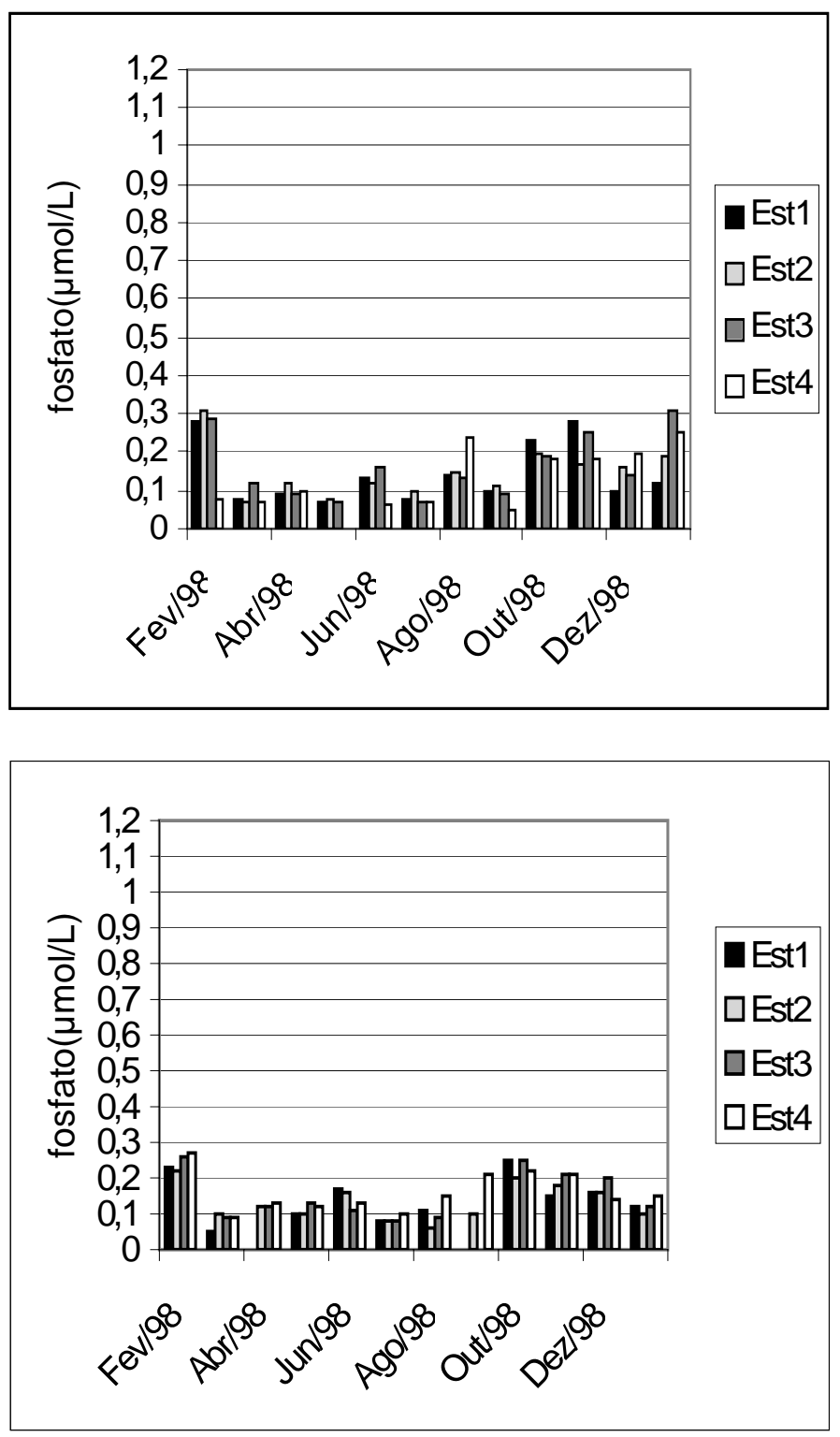

Fig. 8 - Variação sazonal e espacial do fosfato nos estuários dos rios Ilhetas e Mamucaba e na baía de Tamandaré.

Tropical Oceanography, Recife: v. 31, n. 1, p. 1-26, 2003 

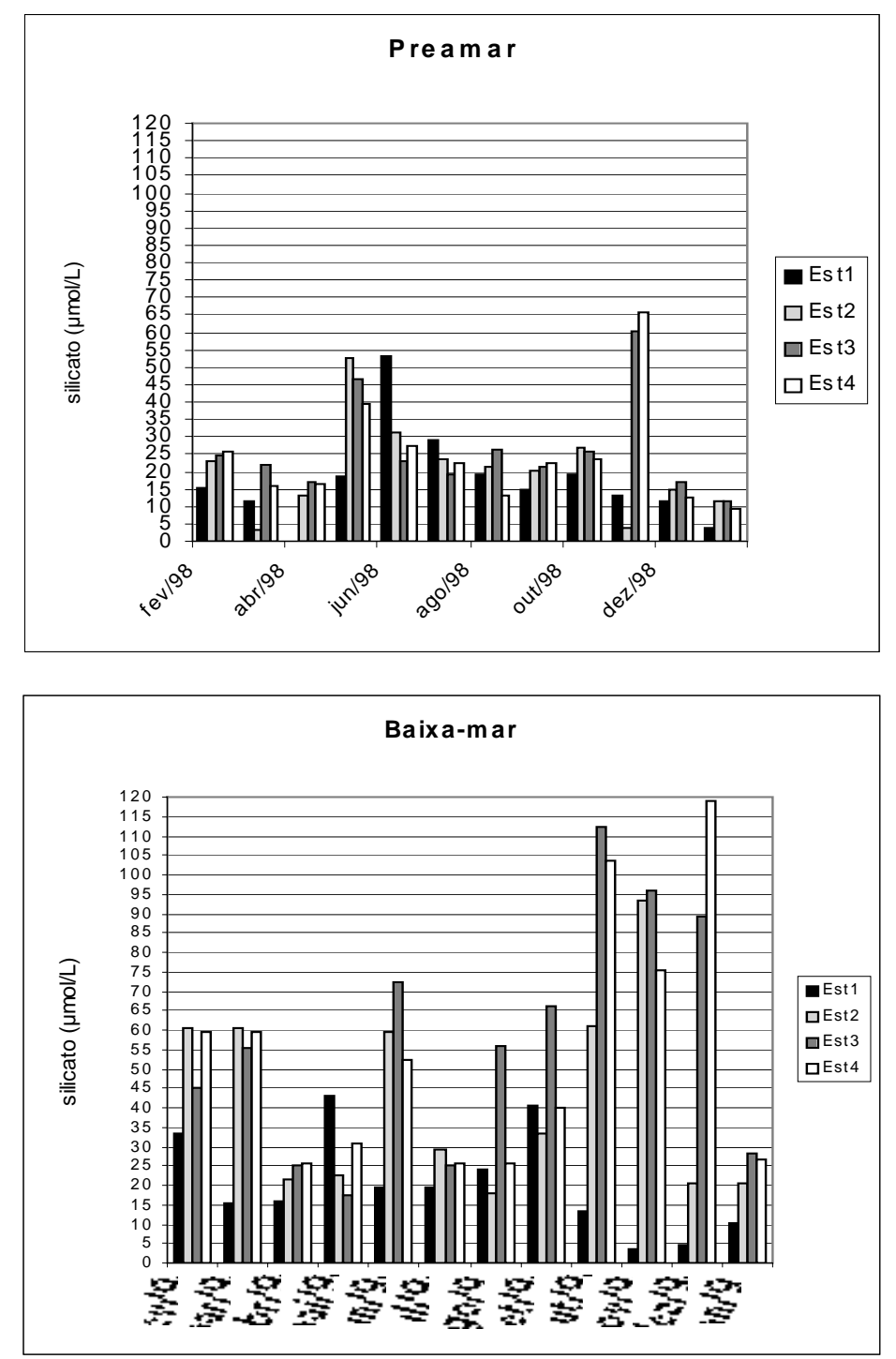

Figura 9 - Variação sazonal e espacial das concentrações do silicato nos estuários dos rios Ilhetas e Mamucaba e na Baía de Tamandaré-PE.

Tropical Oceanography, Recife: v. 31, n. 1, p. 1-26, 2003 

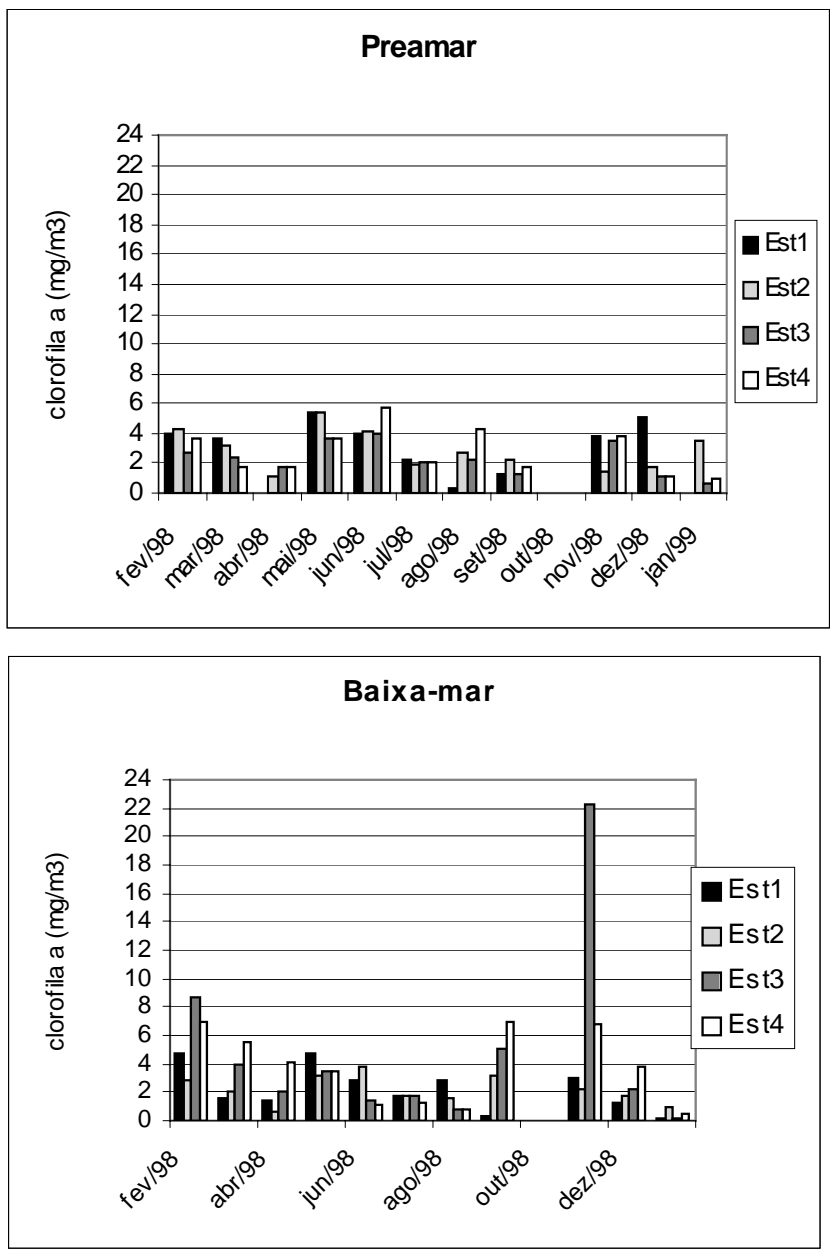

Figura 10 - Variação sazonal e espacial das concentrações da clorofila $a$, nos estuários dos rios Ilhetas e Mamucaba e na Baía de Tamandaré-PE.

Tropical Oceanography, Recife: v. 31, n. 1, p. 1-26, 2003 
Tabela 1 - Parâmetros hidrológicos da estação 1 ( baía de Tamandaré) na preamar.

\begin{tabular}{|c|c|c|c|c|c|c|c|c|c|c|c|c|c|c|c|}
\hline \multirow[t]{2}{*}{ Mês } & \multirow{2}{*}{\begin{tabular}{|c} 
Hora \\
de \\
coleta
\end{tabular}} & \multirow{2}{*}{$\begin{array}{l}\text { Prof. } \\
\text { local }\end{array}$} & \multirow{2}{*}{$\begin{array}{l}\text { Disco de } \\
\text { Secchi }\end{array}$} & \multirow{2}{*}{$\begin{array}{c}\text { Coef. de } \\
\text { ext. da } \\
\text { luz }\end{array}$} & \multirow[t]{2}{*}{ Temp. } & \multirow[t]{2}{*}{ Salin. } & \multirow[t]{2}{*}{$\mathrm{PH}$} & \multicolumn{2}{|c|}{ Oxig. Dissolv. } & \multirow[t]{2}{*}{ DBO } & \multirow{2}{*}{$\begin{array}{c}\text { Nitrito } \\
\mu_{\text {mol.L }}{ }^{-1}\end{array}$} & \multirow{2}{*}{$\begin{array}{c}\text { Nitrato } \\
\text { Hmol.L }^{-1}\end{array}$} & \multirow{2}{*}{$\begin{array}{l}\text { Fosfato } \\
\mu m o l . L^{-1}\end{array}$} & \multirow{2}{*}{$\begin{array}{l}\text { Silicato } \\
\mu m o l . L^{-1}\end{array}$} & \multirow{2}{*}{$\begin{array}{c}\begin{array}{l}\text { Mat. em } \\
\text { susp. }\end{array} \\
\text { mg.L }{ }^{-1}\end{array}$} \\
\hline & & & & & & & & Conc. & Satur. & & & & & & \\
\hline Fev/98 & $08: 15$ & 6,00 & 3,00 & 0,57 & 29,5 & 34 & 8,00 & 4,76 & 107,81 & - & 0,02 & 3,74 & 0,23 & 15,44 & 3,0 \\
\hline Mar/98 & $07: 30$ & 7,30 & 3,00 & 0,57 & 30,0 & 35 & 8,54 & 3,81 & 87,59 & 0,00 & 0,02 & 1,33 & 0,05 & 11,49 & 2,0 \\
\hline Abr/98 & - & - & - & - & - & - & - & - & - & - & - & - & - & - & - \\
\hline Maio/98 & $08: 00$ & 6,60 & 2,00 & 0,85 & 28,5 & 34 & 8,26 & 4,38 & 97,66 & 0,00 & 0,10 & 1,79 & 0,10 & 18,56 & 15,0 \\
\hline Jun/98 & 07:50 & 7,70 & 1,80 & 0,94 & 27,5 & 32 & 8,42 & 4,82 & 104,56 & 0,00 & 0,14 & 2,32 & 0,17 & 53,03 & 5,0 \\
\hline $\mathrm{Jul} / 98$ & 09:05 & 7,30 & 2,00 & 0,85 & 27,2 & 32 & 8,32 & 5,08 & 109,72 & 0,00 & 0,01 & 0,61 & 0,08 & 29,07 & 4,0 \\
\hline Ago/98 & $08: 40$ & 8,00 & 3,00 & 0,57 & 26,8 & 32 & 8,29 & 5,18 & 111,16 & 0,13 & 0,02 & 0,91 & 0,11 & 18,97 & 9,0 \\
\hline Set/98 & $08: 15$ & 7,30 & 4,70 & 0,36 & 27,0 & 33 & 7,90 & 5,49 & 118,83 & 0,57 & 0,05 & 0,91 & 0,00 & 14,95 & 2,0 \\
\hline Out/98 & $06: 40$ & 7,90 & 3,00 & 0,57 & 28,0 & 35 & 8,17 & 4,92 & 109,33 & 0,39 & 0,11 & 0,50 & 0,25 & 19,02 & 5,0 \\
\hline Nov/98 & $07: 55$ & 7,50 & 3,00 & 0,57 & 28,5 & 35 & 8,25 & 5,63 & 126,23 & 0,83 & 0,04 & 0,08 & 0,15 & 13,31 & 2,0 \\
\hline Dez/98 & $07: 00$ & 8,00 & 3,00 & 0,57 & 27,5 & 35 & 8,27 & 4,64 & 102,32 & 0,00 & 0,04 & 0,22 & 0,16 & 11,73 & 4,0 \\
\hline Jan/99 & $06: 40$ & 7,50 & 2,50 & 0,68 & 28,2 & 35 & 8,17 & 5,47 & 122,10 & 0,66 & 0,03 & 0,22 & 0,12 & 3,72 & 2,0 \\
\hline Média & - & 7,37 & 2,82 & 0,64 & 28,06 & 33,82 & 8,24 & 4,92 & 108,85 & 0,26 & 0,05 & 1,15 & 0,13 & 19,03 & 4,88 \\
\hline
\end{tabular}


Tabela 2 - Parâmetros hidrológicos da estação 1 (baía de Tamandaré) na baixa-mar

\begin{tabular}{|c|c|c|c|c|c|c|c|c|c|c|c|c|c|c|c|}
\hline \multirow{2}{*}{$\begin{array}{l}\text { Mês } \\
\text { Ano }\end{array}$} & \multirow{2}{*}{$\begin{array}{c}\begin{array}{c}\text { Hora } \\
\text { de }\end{array} \\
\end{array}$} & \multirow{2}{*}{$\begin{array}{l}\text { Prof. } \\
\text { local } \\
\text { (m) }\end{array}$} & \multirow{2}{*}{$\begin{array}{c}\text { Transp. } \\
\text { da água } \\
\text { (m) }\end{array}$} & \multirow{2}{*}{$\begin{array}{c}\text { Coef. de } \\
\text { ext. da } \\
\text { luz }\end{array}$} & \multirow{2}{*}{$\begin{array}{l}\text { Temp. } \\
\left({ }^{\circ} \mathrm{C}\right)\end{array}$} & \multirow{2}{*}{$\begin{array}{l}\text { Salin. } \\
(\%)\end{array}$} & \multirow{2}{*}{$\mathrm{pH}$} & \multicolumn{2}{|c|}{ Oxig. Dissolv. } & \multirow{2}{*}{$\begin{array}{c}\text { DBO } \\
\left(\mathrm{mg} \cdot \mathrm{L}^{-1}\right)\end{array}$} & \multirow{2}{*}{$\begin{array}{c}\text { Nitrito } \\
\mu \text { mol. } L^{-1}\end{array}$} & \multirow{2}{*}{$\begin{array}{l}\text { Nitrato } \\
\mu \mathrm{mol} . \mathrm{L}^{-1}\end{array}$} & \multirow{2}{*}{$\begin{array}{l}\text { Fosfato } \\
\mu \operatorname{mol}_{1} L^{-}\end{array}$} & \multirow{2}{*}{$\begin{array}{l}\text { Silicato } \\
\mu \mathrm{mol} . \mathrm{L}^{-1}\end{array}$} & \multirow{2}{*}{$\begin{array}{l}\text { Mat. em } \\
\text { susp. } \\
\text { total } \\
\text { mg.. }{ }^{-1}\end{array}$} \\
\hline & & & & & & & & Conc. & Satur. & & & & & & \\
\hline Fev/98 & $13: 00$ & 5,50 & 2,50 & 0,68 & 31,0 & 36 & 8,65 & 4,52 & 106,10 & _- & 0,01 & 1,71 & 0,28 & 33,31 & 14,0 \\
\hline Mar/98 & $11: 40$ & 6,70 & 3,50 & 0,48 & 30,5 & 36 & 8,51 & 4,59 & 106,87 & 0,43 & 0,00 & 1,30 & 0,08 & 15,13 & 3,0 \\
\hline Abr/98 & $11: 50$ & 5,80 & 3,10 & 0,55 & 29,5 & 33 & 8,46 & 4,74 & 106,88 & 0,77 & 0,01 & 0,68 & 0,09 & 16,14 & 10,0 \\
\hline Maio/98 & $12: 20$ & 5,80 & 1,50 & 1,13 & 29,0 & 30 & 8,18 & 4,48 & 98,46 & - & 0,12 & 0,96 & 0,07 & 43,20 & 18,0 \\
\hline Jun/98 & $12: 10$ & 6,60 & 1,75 & 0,97 & 27,0 & 32 & 8,36 & 5,41 & 116,34 & 0,45 & 0,12 & 1,56 & 0,13 & 19,27 & 12,0 \\
\hline $\mathrm{Jul} / 98$ & $12: 55$ & 6,10 & 4,00 & 0,42 & 28,0 & 32 & 8,23 & 5,27 & 115,32 & 0,29 & 0,06 & 0,70 & 0,08 & 19,35 & 4,0 \\
\hline Ago/98 & $13: 50$ & 6,00 & 3,00 & 0,57 & 27,0 & 30 & 8,26 & 5,61 & 119,36 & 0,59 & 0,06 & 1,73 & 0,14 & 24,21 & 4,0 \\
\hline Set/98 & $12: 26$ & 5,70 & 2,20 & 0,77 & 28,0 & 30 & 8,02 & 5,47 & 118,40 & 0,10 & 0,01 & 0,78 & 0,10 & 40,34 & 10,0 \\
\hline Out/98 & $10: 56$ & 5,20 & 4,50 & 0,38 & 30,0 & 34 & 8,20 & 5,65 & 129,00 & 1,22 & 0,05 & 0,42 & 0,23 & 13,28 & 1,0 \\
\hline Nov/98 & $13: 10$ & 5,50 & 2,70 & 0,63 & 29,0 & 33 & 8,29 & 5,51 & 123,27 & 0,50 & 0,01 & 0,00 & 0,28 & 3,72 & 4,0 \\
\hline Dez/98 & $11: 45$ & 6,00 & 2,20 & 0,77 & 28,0 & 34 & 8,02 & 5,28 & 116,81 & 0,38 & 0,00 & 0,14 & 0,10 & 4,51 & 5,0 \\
\hline Jan/99 & $11: 00$ & 6,00 & 2,50 & 0,68 & 28,0 & 35 & 8,21 & 5,54 & 123,11 & 0,38 & 0,03 & 0,12 & 0,12 & 10,46 & 3,0 \\
\hline Média & - & 5,91 & 2,79 & 0,67 & 28,75 & 32,92 & 8,28 & 5,17 & 114,99 & 0,51 & 0,04 & 0,84 & 0,14 & 20,24 & 7,38 \\
\hline
\end{tabular}


Tabela 3 - Parâmetros hidrológicos da estação 2 (confluência) na preamar

\begin{tabular}{|c|c|c|c|c|c|c|c|c|c|c|c|c|c|c|c|}
\hline \multirow{2}{*}{$\begin{array}{l}\text { Mês } \\
\text { Ano }\end{array}$} & \multirow{2}{*}{$\begin{array}{l}\text { Hora } \\
\text { de } \\
\text { coleta }\end{array}$} & \multirow{2}{*}{$\begin{array}{l}\text { Prof. } \\
\text { local } \\
\text { (m) }\end{array}$} & \multirow{2}{*}{$\begin{array}{l}\text { Transp. } \\
\text { da água } \\
\text { (m) }\end{array}$} & \multirow{2}{*}{$\begin{array}{l}\text { Coef. de } \\
\text { ext. da } \\
\text { luz }\end{array}$} & \multirow{2}{*}{$\begin{array}{l}\text { Temp. } \\
\left({ }^{\circ} \mathrm{C}\right)\end{array}$} & \multirow{2}{*}{$\begin{array}{l}\text { Salin. } \\
\text { (\%o) }\end{array}$} & \multirow{2}{*}{$\mathrm{pH}$} & \multicolumn{2}{|c|}{ Oxig. Dissolv. } & \multirow{2}{*}{$\begin{array}{l}\text { DBO } \\
\mathrm{mg} \cdot \mathrm{L}^{-1}\end{array}$} & \multirow{2}{*}{$\begin{array}{c}\text { Nitrito } \\
\mu \text { mol. } L^{-1}\end{array}$} & \multirow{2}{*}{$\begin{array}{l}\text { Nitrato } \\
\mu \text { mol. } L^{-1}\end{array}$} & \multirow{2}{*}{$\begin{array}{l}\text { Fosfato } \\
\mu \mathrm{mol} . \mathrm{L}^{-1}\end{array}$} & \multirow{2}{*}{$\begin{array}{c}\text { Silicato } \\
\mu \mathrm{mol} . \mathrm{L}^{-1}\end{array}$} & \multirow{2}{*}{$\begin{array}{c}\text { Mat. em } \\
\text { susp. } \\
\text { total } \\
\text { mg.L }{ }^{-1}\end{array}$} \\
\hline & & & & & & & & Conc. & Satur. & & & & & & \\
\hline Fev/98 & 8:00 & 1,20 & 1,20 & 1,42 & 29,0 & 34 & 8,17 & 4,52 & 101,57 & - & 0,06 & 0,31 & 0,22 & 22,86 & 4,0 \\
\hline Mar/98 & $07: 20$ & 1,70 & 1,70 & 1,00 & 29,5 & 33 & 8,42 & 4,14 & 93,35 & 0,25 & 0,01 & 1,33 & 0,10 & 3,21 & 3,0 \\
\hline $\mathrm{Abr} / 98$ & 07:00 & 1,10 & 1,10 & 1,54 & 29,0 & 33 & 7,86 & 4,38 & 97,99 & 0,99 & 0,00 & 1,19 & 0,12 & 13,10 & 10,0 \\
\hline Mai/98 & $07: 50$ & 1,00 & 1,00 & 1,70 & 28,0 & 28 & 8,22 & 3,87 & 82,87 & - & 0,12 & 1,06 & 0,10 & 52,86 & 11,0 \\
\hline Jun/98 & $07: 30$ & 1,00 & 1,00 & 1,70 & 27,0 & 31 & 8,37 & 5,36 & 114,78 & 0,00 & 0,11 & 1,50 & 0,16 & 31,15 & 6,0 \\
\hline $\mathrm{Jul} / 98$ & $08: 55$ & 2,30 & 2,30 & 0,74 & 27,2 & 32 & 8,22 & 3,89 & 84,02 & 0,00 & 0,03 & 0,61 & 0,08 & 23,37 & 6,0 \\
\hline Ago/98 & $08: 25$ & 3,00 & 1,50 & 1,13 & 26,5 & 27 & 6,80 & 5,43 & 112,66 & 0,50 & 0,11 & 1,48 & 0,06 & 21,21 & 13,0 \\
\hline Set/98 & $07: 55$ & 2,50 & 2,00 & 0,85 & 27,1 & 31 & 8,03 & 5,57 & 119,40 & 0,66 & 0,03 & 1,63 & 0,10 & 20,32 & 5,0 \\
\hline Out/98 & $06: 20$ & 2,12 & 2,12 & 0,80 & 27,5 & 32 & 8,18 & 5,12 & 111,06 & 0,53 & 0,03 & 0,56 & 0,20 & 26,75 & 5,0 \\
\hline Nov/98 & $07: 30$ & 2,00 & 2,00 & 0,85 & 28,5 & 33 & 8,13 & 5,77 & 127,94 & 1,29 & 0,00 & 0,21 & 0,18 & 3,98 & 5,0 \\
\hline Dez/98 & $06: 45$ & 2,00 & 1,50 & 1,13 & 27,7 & 34 & 8,07 & 5,71 & 125,63 & 0,76 & 0,02 & 0,19 & 0,16 & 14,69 & 5,0 \\
\hline Jan/99 & $06: 20$ & 1,50 & 1,50 & 1,13 & 28,0 & 35 & 8,41 & 5,22 & 116,00 & 0,13 & 0,00 & 0,66 & 0,10 & 11,24 & 5,0 \\
\hline Média & - & 1,78 & 1,58 & 1,16 & 27,92 & 31,92 & 8,07 & 4,92 & 107,27 & 0,51 & 0,10 & 0,89 & 0,13 & 20,40 & 6,43 \\
\hline
\end{tabular}


Tabela 4 - Parâmetros hidrológicos da estação 2 (confluência) na baixa-mar.

\begin{tabular}{|c|c|c|c|c|c|c|c|c|c|c|c|c|c|c|c|}
\hline \multirow{2}{*}{$\begin{array}{l}\text { Mês } \\
\text { Ano }\end{array}$} & \multirow{2}{*}{$\begin{array}{l}\text { Hora } \\
\text { de } \\
\text { coleta }\end{array}$} & \multirow{2}{*}{$\begin{array}{c}\text { Prof. } \\
\text { local } \\
\text { (m) }\end{array}$} & \multirow{2}{*}{$\begin{array}{c}\text { Transp. } \\
\text { da água } \\
\text { (m) }\end{array}$} & \multirow{2}{*}{$\begin{array}{c}\text { Coef. } \\
\text { de ext. } \\
\text { da luz }\end{array}$} & \multirow{2}{*}{$\begin{array}{l}\text { Temp. } \\
\left({ }^{\circ} \mathrm{C}\right)\end{array}$} & \multirow{2}{*}{$\begin{array}{l}\text { Salin. } \\
(\%)\end{array}$} & \multirow{2}{*}{$\mathrm{pH}$} & \multicolumn{2}{|c|}{ Oxig. Dissolv. } & \multirow{2}{*}{$\begin{array}{l}\text { DBO } \\
\mathrm{mg} \cdot \mathrm{L}^{-1}\end{array}$} & \multirow{2}{*}{$\begin{array}{c}\text { Nitrito } \\
\mu \mathrm{mol} . L^{-1}\end{array}$} & \multirow{2}{*}{$\begin{array}{l}\text { Nitrato } \\
\mu \mathrm{mol} . L^{-1}\end{array}$} & \multirow{2}{*}{$\begin{array}{l}\text { Fosfato } \\
\mu \mathrm{mol} . \mathrm{L}^{-1}\end{array}$} & \multirow{2}{*}{$\begin{array}{l}\text { Silicato } \\
\mu m o l . L^{-1}\end{array}$} & \multirow{2}{*}{$\begin{array}{l}\text { Mat. em } \\
\text { susp. } \\
\text { total } \\
\text { mg. } .^{-1}\end{array}$} \\
\hline & & & & & & & & $\begin{array}{c}\text { Conc. } \\
\left(\mathrm{ml} . \mathrm{L}^{-1}\right)\end{array}$ & $\begin{array}{c}\text { Satur. } \\
(\%)\end{array}$ & & & & & & \\
\hline $\mathrm{Fev} / 98$ & $13: 40$ & 0,60 & 0,60 & 2,83 & 32,0 & 16 & 7,78 & 4,29 & 91,67 & - & 0,11 & 0,97 & 0,31 & 60,72 & 4,0 \\
\hline Mar/98 & $12: 00$ & 1,30 & 1,30 & 1,31 & 31,0 & 20 & 8,35 & 4,52 & 97,20 & 0,38 & 0,01 & 1,15 & 0,07 & 60,34 & 3,0 \\
\hline Abr/98 & $12: 15$ & 0,60 & 0,60 & 2,83 & 31,5 & 20 & 7,93 & 4,06 & 87,41 & 0,62 & 0,02 & 1,61 & 0,12 & 21,34 & 9,0 \\
\hline Mai/98 & $12: 40$ & 1,30 & 0,40 & 4,25 & 27,0 & 2 & 7,27 & 0,80 & 14,54 & - & 0,16 & 0,59 & 0,08 & 22,56 & 44,0 \\
\hline Jun/98 & $12: 30$ & 0,55 & 0,55 & 3,09 & 27,5 & 23 & 8,22 & 4,82 & 99,38 & 1,12 & 0,09 & 1,19 & 0,12 & 54,30 & 6,0 \\
\hline $\mathrm{Jul} / 98$ & $13: 14$ & 1,00 & 1,00 & 1,70 & 28,0 & 22 & 8,26 & 4,40 & 91,10 & 0,29 & 0,06 & 1,02 & 0,10 & 29,32 & 3,0 \\
\hline Ago/98 & $14: 15$ & 0,70 & 0,30 & 5,67 & 26,2 & 1 & 8,18 & 1,91 & 34,05 & 0,11 & 0,05 & 1,45 & 0,15 & 17,92 & 31,0 \\
\hline Set/98 & $12: 55$ & 1,00 & 1,00 & 1,70 & 26,0 & 16 & 7,64 & 4,29 & 82,98 & 0,00 & 0,05 & 1,10 & 0,11 & 33,39 & 20,0 \\
\hline Out/98 & $11: 20$ & 1,00 & 1,00 & 1,70 & 29,0 & 26 & 8,07 & 5,01 & 107,74 & 1,29 & 0,04 & 0,47 & 0,20 & 61,06 & 6,0 \\
\hline Nov/98 & $13: 40$ & 0,80 & 0,80 & 2,12 & 30,0 & 13 & 7,67 & 5,36 & 109,16 & 0,71 & 0,02 & 0,02 & 0,17 & 93,44 & 4,0 \\
\hline Dez/98 & $12: 05$ & 0,80 & 0,80 & 2,12 & 29,0 & 27 & 7,95 & 5,07 & 109,74 & 0,55 & 0,04 & 0,36 & 0,16 & 20,36 & 3,0 \\
\hline Jan/99 & $11: 20$ & 0,80 & 0,80 & 2,12 & 29,0 & 32 & 8,54 & 5,01 & 111,33 & 0,90 & 0,05 & 0,29 & 0,19 & 20,73 & 3,0 \\
\hline Média & - & 0,87 & 0,76 & 2,62 & 28,85 & 18,17 & 7,99 & 4,13 & 86,36 & 0,60 & 0,06 & 0,85 & 0,15 & 41,29 & 11,34 \\
\hline
\end{tabular}


Tabela 5 - Parâmetros hidrológicos da estação 3 (estuário do rio Ilhetas) na preamar.

\begin{tabular}{|c|c|c|c|c|c|c|c|c|c|c|c|c|c|c|c|}
\hline \multirow{2}{*}{$\begin{array}{l}\text { Mês } \\
\text { Ano } \\
\end{array}$} & \multirow{2}{*}{$\begin{array}{c}\text { Hora } \\
\text { de } \\
\text { coleta }\end{array}$} & \multirow{2}{*}{$\begin{array}{c}\text { Prof. } \\
\text { local } \\
(\mathrm{m})\end{array}$} & \multirow{2}{*}{$\begin{array}{c}\text { Transp. } \\
\text { da água } \\
\text { (m) }\end{array}$} & \multirow{2}{*}{$\begin{array}{l}\text { Coef. } \\
\text { de ext. } \\
\text { da luz }\end{array}$} & \multirow{2}{*}{$\begin{array}{l}\text { Temp. } \\
\left({ }^{\circ} \mathrm{C}\right)\end{array}$} & \multirow{2}{*}{$\begin{array}{l}\text { Salin. } \\
(\%) \\
\end{array}$} & \multirow{2}{*}{$\mathrm{pH}$} & \multicolumn{2}{|c|}{ Oxig. Dissolv. } & \multirow{2}{*}{$\begin{array}{c}\text { DBO } \\
\left(\mathrm{mg}^{-L^{-1}}\right)\end{array}$} & \multirow{2}{*}{$\begin{array}{c}\text { Nitrito } \\
\mu \mathrm{mol.L} \text { - }^{-1}\end{array}$} & \multirow{2}{*}{$\begin{array}{l}\text { Nitrato } \\
\mu \mathrm{mol.L}{ }^{-1}\end{array}$} & \multirow{2}{*}{$\begin{array}{l}\text { Fosfato } \\
\mu^{\text {mol.L }}{ }^{-1}\end{array}$} & \multirow{2}{*}{$\begin{array}{l}\text { Silicato } \\
\mu m o l . L^{-1}\end{array}$} & \multirow{2}{*}{$\begin{array}{l}\text { Mat. em } \\
\text { susp. } \\
\text { total } \\
\text { mg. } .^{-1} \\
\end{array}$} \\
\hline & & & & & & & & Conc. & Satur. & & & & & & \\
\hline Fev/98 & $07: 40$ & 1,00 & 1,00 & 1,70 & 29,0 & 34 & 8,15 & 4,51 & 101,35 & - & 0,02 & 0,48 & 0,26 & 24,39 & 4,0 \\
\hline Mar/98 & $07: 00$ & 1,40 & 1,40 & 1,21 & 29,0 & 33 & 8,46 & 3,97 & 88,81 & 0,20 & 0,01 & 1,50 & 0,09 & 22,10 & 4,0 \\
\hline Abr/98 & $06: 35$ & 1,00 & 1,00 & 1,70 & 29,0 & 30 & 8,08 & 4,21 & 92,53 & 0,80 & 0,04 & 0,73 & 0,12 & 17,24 & 12,0 \\
\hline Mai/98 & $07: 30$ & 1,30 & 1,00 & 1,70 & 28,0 & 26 & 8,20 & 3,91 & 82,66 & - & 0,12 & 1,27 & 0,13 & 46,78 & 23,0 \\
\hline Jun/98 & $07: 15$ & 1,40 & 1,40 & 1,21 & 26,5 & 31 & 8,26 & 5,14 & 109,01 & 0,71 & 0,10 & 1,00 & 0,11 & 23,07 & 7,0 \\
\hline $\mathrm{Jul} / 98$ & $08: 35$ & 1,10 & 1,10 & 1,54 & 27,0 & 32 & 8,22 & 4,98 & 107,10 & 0,01 & 0,04 & 0,50 & 0,08 & 19,18 & 2,0 \\
\hline Ago/98 & 08:10 & 1,10 & 1,10 & 1,54 & 26,0 & 29 & 7,47 & 4,96 & 103,12 & 0,03 & 0,99 & 2,80 & 0,09 & 26,20 & 12,0 \\
\hline Set/98 & $07: 35$ & 1,00 & 1,00 & 1,70 & 27,0 & 31 & 8,10 & 5,18 & 110,92 & 0,15 & 0,04 & 0,93 & 0,00 & 21,60 & 3,0 \\
\hline Out/98 & 06:10 & 1,17 & 1,17 & 1,45 & 27,0 & 32 & 7,74 & 5,02 & 107,96 & 0,22 & 0,04 & 0,54 & 0,25 & 25,85 & 3,0 \\
\hline Nov/98 & 07:15 & 1,00 & 1,00 & 1,70 & 28,0 & 26 & 7,91 & 5,63 & 119,03 & 1,62 & 0,02 & 0,44 & 0,21 & 60,47 & 4,0 \\
\hline Dez/98 & $06: 25$ & 1,00 & 1,00 & 1,70 & 28,0 & 34 & 8,00 & 5,71 & 126,33 & 0,83 & 0,02 & 0,31 & 0,20 & 16,75 & 4,0 \\
\hline Jan/99 & 06:05 & 1,20 & 1,20 & 1,42 & 28,0 & 35 & 8,33 & 5,33 & 118,44 & 0,83 & 0,03 & 0,32 & 0,12 & 11,47 & 4,0 \\
\hline Média & - & 1,12 & 1,11 & 1,55 & 27,71 & 31,08 & 8,08 & 4,88 & 105,60 & 0,54 & 0,12 & 0,90 & 0,14 & 26,26 & 6,92 \\
\hline
\end{tabular}


Tabela 6 - Parâmetros hidrológicos da estação 3 (estuário do rio Ilhetas) na baixa-mar

\begin{tabular}{|c|c|c|c|c|c|c|c|c|c|c|c|c|c|c|c|}
\hline \multirow{2}{*}{$\begin{array}{l}\text { Mês } \\
\text { Ano } \\
\end{array}$} & \multirow{2}{*}{$\begin{array}{c}\text { Hora } \\
\text { de } \\
\text { coleta }\end{array}$} & \multirow{2}{*}{$\begin{array}{c}\text { Prof. } \\
\text { local } \\
(\mathrm{m})\end{array}$} & \multirow{2}{*}{$\begin{array}{l}\text { Transp. } \\
\text { da água }\end{array}$} & \multirow{2}{*}{$\begin{array}{c}\text { Coef. de } \\
\text { ext. da } \\
\text { luz }\end{array}$} & \multirow{2}{*}{$\begin{array}{l}\text { Temp. } \\
\left({ }^{\circ} \mathrm{C}\right)\end{array}$} & \multirow{2}{*}{$\begin{array}{l}\text { Salin. } \\
(\%) \\
\end{array}$} & \multirow{2}{*}{$\mathrm{pH}$} & \multicolumn{2}{|c|}{ Oxig. Dissolv. } & \multirow{2}{*}{$\begin{array}{c}\text { DBO } \\
\left(\mathrm{mg}^{-L^{-1}}\right)\end{array}$} & \multirow{2}{*}{$\begin{array}{c}\text { Nitrito } \\
\text { umol.L }^{-1}\end{array}$} & \multirow{2}{*}{$\begin{array}{l}\text { Nitrato } \\
\mu m o l . L^{-1}\end{array}$} & \multirow{2}{*}{$\begin{array}{l}\text { Fosfato } \\
\mu_{\text {mol.L }}^{-1}\end{array}$} & \multirow{2}{*}{$\begin{array}{l}\text { Silicato } \\
\mu \mathrm{mol.L}{ }^{-1}\end{array}$} & \multirow{2}{*}{$\begin{array}{c}\text { Mat. } \\
\text { em } \\
\text { susp. } \\
\text { total }\end{array}$} \\
\hline & & & & & & & & Conc. & Satur. & & & & & & \\
\hline Fev/98 & $14: 15$ & 0,40 & 0,40 & 4,25 & 32,0 & 7 & 8,00 & 4,27 & 86,96 & - & 0,08 & 1,60 & 0,29 & 44,93 & 9,0 \\
\hline Mar/98 & $12: 50$ & 0,80 & 0,80 & 2,12 & 31,0 & 6 & 7,70 & 5,47 & 108,96 & 2,67 & 0,04 & 3,02 & 0,12 & 55,39 & 7,0 \\
\hline Abr/98 & $12: 45$ & 0,40 & 0,40 & 4,25 & 31,0 & 6 & 7,32 & 3,63 & 72,31 & 0,76 & 0,08 & 1,45 & 0,09 & 25,14 & 9,0 \\
\hline Mai/98 & $13: 00$ & 0,70 & 0,30 & 5,67 & 27,8 & 0 & 6,92 & 0,42 & 07,66 & - & 0,24 & 0,94 & 0,07 & 17,46 & 56,0 \\
\hline Jun/98 & $13: 05$ & 0,50 & 0,50 & 3,4 & 27,0 & 5 & 7,40 & 4,51 & 83,36 & 0,85 & 0,10 & 2,31 & 0,16 & 72,38 & 15,0 \\
\hline $\mathrm{Jul} / 98$ & $13: 40$ & 0,60 & 0,60 & 2,83 & 27,0 & 5 & 7,55 & 3,88 & 71,72 & 0,00 & 0,11 & 2,42 & 0,07 & 25,14 & 7,0 \\
\hline Ago/98 & $14: 50$ & 0,40 & 0,20 & 8,5 & 26,0 & 0 & 7,33 & 1,22 & 21,55 & 0,00 & 0,20 & 0,56 & 0,13 & 55,98 & 30,0 \\
\hline Set/98 & $13: 20$ & 0,60 & 0,60 & 2,83 & 26,0 & 1 & 7,08 & 3,94 & 69,98 & 0,14 & 0,03 & 1,15 & 0,09 & 66,24 & 14,0 \\
\hline Out/98 & $11: 50$ & 0,80 & 0,80 & 2,12 & 29,0 & 12 & 8,17 & 4,93 & 98,21 & 0,43 & 0,04 & 0,58 & 0,19 & 112,54 & 3,0 \\
\hline Nov/98 & $14: 16$ & 0,60 & 0,60 & 2,83 & 30,0 & 3 & 7,51 & 5,28 & 101,73 & 2,58 & 0,03 & 0,00 & 0,25 & 96,07 & 4,0 \\
\hline Dez/98 & $12: 30$ & 0,50 & 0,50 & 3,4 & 29,0 & 10 & 7,63 & 5,07 & 99,80 & 0,66 & 0,02 & 0,50 & 0,14 & 89,44 & 6,0 \\
\hline Jan/99 & $11: 55$ & 0,70 & 0,70 & 2,43 & 29,0 & 21 & 8,36 & 4,25 & 88,91 & 0,52 & 0,00 & 0,76 & 0,31 & 28,39 & 3,0 \\
\hline Média & - & 0,58 & 0,53 & 3,72 & 28,73 & 6,33 & 7,58 & 3,90 & 75,93 & 0,86 & 0,08 & 1,27 & 0,16 & 57,42 & 13,5 \\
\hline
\end{tabular}


Tabela 7 - Parâmetros hidrológicos da estação 4 (estuário do rio Mamucaba) na preamar

\begin{tabular}{|c|c|c|c|c|c|c|c|c|c|c|c|c|c|c|c|}
\hline \multirow{2}{*}{$\begin{array}{l}\text { Mês } \\
\text { Ano }\end{array}$} & \multirow{2}{*}{$\begin{array}{l}\text { Hora } \\
\text { de } \\
\text { coleta }\end{array}$} & \multirow{2}{*}{$\begin{array}{l}\text { Prof. } \\
\text { local }\end{array}$} & \multirow{2}{*}{$\begin{array}{c}\text { Transp. } \\
\text { da } \\
\text { água }\end{array}$} & \multirow{2}{*}{$\begin{array}{c}\text { Coef. de } \\
\text { ext. da } \\
\text { luz }\end{array}$} & \multirow{2}{*}{$\begin{array}{c}\text { Temp. } \\
\left({ }^{\circ} \mathrm{C}\right)\end{array}$} & \multirow{2}{*}{$\begin{array}{l}\text { Salin. } \\
(\%)\end{array}$} & \multirow{2}{*}{$\mathrm{pH}$} & \multicolumn{2}{|c|}{ Oxig. Dissolv. } & \multirow{2}{*}{$\begin{array}{c}\text { DBO } \\
\left(\mathrm{mg}^{-1} \mathrm{~L}^{-1}\right)\end{array}$} & \multirow{2}{*}{$\begin{array}{c}\text { Nitrito } \\
\mu_{\text {mol.L }}^{-1}\end{array}$} & \multirow{2}{*}{$\begin{array}{l}\text { Nitrato } \\
\mu \mathrm{mol} . \mathrm{L}^{-1}\end{array}$} & \multirow{2}{*}{$\begin{array}{l}\text { Fosfato } \\
\mu_{\text {mol.L }}{ }^{-1}\end{array}$} & \multirow{2}{*}{$\begin{array}{l}\text { Silicato } \\
\mu \mathrm{mol} . \mathrm{L}^{-1}\end{array}$} & \multirow{3}{*}{$\begin{array}{c}\text { Mat. em } \\
\text { susp. } \\
\text { total } \\
\text { mg. } L^{-1} \\
7,0\end{array}$} \\
\hline & & & & & & & & Conc. & Satur. & & & & & & \\
\hline Fev/98 & $07: 10$ & 0,90 & 0,90 & 1,89 & 29,0 & 33 & 8,17 & 4,06 & 90,83 & - & 0,11 & 2,51 & 0,27 & 25,59 & \\
\hline Mar/98 & 06:30 & 1,20 & 1,20 & 1,42 & 29,0 & 34 & 8,49 & 3,97 & 89,21 & 0,01 & 0,01 & 1,48 & 0,09 & 16,14 & 3,0 \\
\hline Abr/98 & 06:10 & 1,00 & 1,00 & 1,70 & 29,0 & 32 & 8,30 & 3,40 & 75,56 & 0,00 & 0,02 & 0,88 & 0,13 & 16,69 & 10,0 \\
\hline Mai/98 & $07: 00$ & 1,00 & 1,00 & 1,70 & 28,0 & 27 & 8,00 & 4,07 & 86,60 & - & 0,10 & 1,52 & 0,12 & 39,22 & 25,0 \\
\hline Jun/98 & $06: 50$ & 1,00 & 1,00 & 1,70 & 26,5 & 31 & 8,44 & 5,24 & 111,13 & 0,56 & 0,10 & 1,48 & 0,13 & 27,17 & 6,0 \\
\hline $\mathrm{Jul} / 98$ & 08:15 & 1,00 & 1,00 & 1,70 & 27,0 & 32 & 8,18 & 5,11 & 109,89 & 0,00 & 0,05 & 0,75 & 0,10 & 22,39 & 6,0 \\
\hline Ago/98 & $07: 46$ & 1,00 & 1,00 & 1,70 & 26,0 & 28 & 8,38 & 5,08 & 105,18 & 0,17 & 0,03 & 1,62 & 0,15 & 13,14 & 12,0 \\
\hline Set/98 & 07:07 & 1,00 & 1,00 & 1,70 & 27,0 & 31 & 8,04 & 5,04 & 107,92 & 0,00 & 0,02 & 1,54 & 0,21 & 22,61 & 6,0 \\
\hline Out/98 & $05: 50$ & 1,30 & 1,30 & 1,31 & 27,0 & 33 & 7,93 & 5,23 & 113,20 & 0,77 & 0,00 & 0,48 & 0,22 & 23,77 & 3,0 \\
\hline Nov/98 & 06:55 & 1,00 & 1,00 & 1,70 & 28,0 & 25 & 7,84 & 5,42 & 114,11 & 1,18 & 0,00 & 0,37 & 0,21 & 65,69 & 6,0 \\
\hline Dez/98 & 06:00 & 0,95 & 0,95 & 1,79 & 27,2 & 33 & 8,05 & 5,07 & 109,98 & 0,43 & 0,03 & 0,44 & 0,14 & 12,80 & 6,0 \\
\hline Jan/99 & $05: 45$ & 1,00 & 1,00 & 1,70 & 28,0 & 35 & 7,94 & 5,02 & 111,56 & 0,34 & 0,02 & 0,88 & 0,15 & 9,31 & 7,0 \\
\hline Média & - & 1,03 & 1,03 & 1,67 & 27,64 & 31,17 & 8,15 & 4,72 & 102,09 & 0,35 & 0,04 & 1,16 & 0,16 & 24,54 & 8,0 \\
\hline
\end{tabular}


Tabela 8 - Parâmetros hidrológicos da estação 4 (estuário do rio Mamucaba) na baixa-mar

\begin{tabular}{|c|c|c|c|c|c|c|c|c|c|c|c|c|c|c|c|}
\hline \multirow{2}{*}{$\begin{array}{l}\text { Mês } \\
\text { Ano }\end{array}$} & \multirow{2}{*}{$\begin{array}{c}\begin{array}{c}\text { Hora } \\
\text { de } \\
\text { coleta }\end{array} \\
\end{array}$} & \multirow{2}{*}{$\begin{array}{c}\text { Prof. } \\
\text { local } \\
\text { (m) }\end{array}$} & \multirow{2}{*}{$\begin{array}{c}\text { Transp. } \\
\text { da } \\
\text { água } \\
\text { (m) } \\
\end{array}$} & \multirow{2}{*}{$\begin{array}{c}\text { Coef. de } \\
\text { ext. da } \\
\text { luz }\end{array}$} & \multirow{2}{*}{$\begin{array}{l}\text { Temp. } \\
\left({ }^{\circ} \mathrm{C}\right)\end{array}$} & \multirow{2}{*}{$\begin{array}{c}\text { Salin. } \\
(\%)\end{array}$} & \multirow{2}{*}{$\mathrm{pH}$} & \multicolumn{2}{|c|}{ Oxig. Dissolv. } & \multirow{2}{*}{$\begin{array}{l}\text { DBO } \\
\text { mg. } L^{-1}\end{array}$} & \multirow{2}{*}{$\begin{array}{c}\text { Nitrito } \\
\mu \mathrm{mol} . L^{-1}\end{array}$} & \multirow{2}{*}{$\begin{array}{l}\text { Nitrato } \\
\mu \mathrm{mol} . L^{-1}\end{array}$} & \multirow{2}{*}{$\begin{array}{c}\text { Fosfato } \\
\mu \mathrm{mol} . \mathrm{L}^{-1}\end{array}$} & \multirow{2}{*}{$\begin{array}{l}\text { Silicato } \\
\mu \text { mol. } .^{-1}\end{array}$} & \multirow{2}{*}{$\begin{array}{c}\text { Mat.em } \\
\text { susp. } \\
\text { total } \\
\text { mg.. }{ }^{-1} \\
\end{array}$} \\
\hline & & & & & & & & $\begin{array}{c}\text { Conc. } \\
\left(\mathrm{ml}^{-} \mathrm{L}^{-1}\right)\end{array}$ & $\begin{array}{c}\text { Satur. } \\
(\%)\end{array}$ & & & & & & \\
\hline Fev/98 & $14: 40$ & 0,30 & 0,30 & 5,67 & 32,0 & 12,5 & 8,20 & 3,83 & 80,29 & - & 0,07 & 1,47 & 0,08 & 59,36 & 8,0 \\
\hline Mar/98 & $13: 40$ & 0,40 & 0,40 & 4,25 & 31,0 & 8 & 7,62 & 3,08 & 62,10 & 0,90 & 0,00 & 2,11 & 0,07 & 59,36 & 11,0 \\
\hline Abr/98 & $13: 20$ & 0,40 & 0,40 & 4,25 & 31,5 & 8 & 7,17 & 4,50 & 91,37 & 2,98 & 0,01 & 1,20 & 0,10 & 25,82 & 14,0 \\
\hline Mai/98 & $13: 50$ & 0,70 & 0,40 & 4,25 & 28,0 & 0 & 6,97 & 1,90 & 34,80 & 0,00 & 0,04 & 1,13 & 0,00 & 30,69 & 25,0 \\
\hline Jun/98 & $13: 40$ & 0,45 & 0,45 & 3,78 & 28,0 & 4 & 7,51 & 3,09 & 57,86 & 0,63 & 0,08 & 1,06 & 0,06 & 52,27 & 18,0 \\
\hline $\mathrm{Jul} / 98$ & $14: 15$ & 0,50 & 0,50 & 3,40 & 26,0 & 5 & 7,54 & 3,12 & 56,62 & 0,00 & 0,10 & 1,30 & 0,07 & 25,52 & 6,0 \\
\hline Ago/98 & 15:35 & 0,60 & 0,30 & 5,67 & 26,0 & 0 & 8,25 & 2,85 & 50,35 & 0,00 & 0,06 & 0,52 & 0,24 & 25,51 & 20,0 \\
\hline Set/98 & $14: 05$ & 0,60 & 0,60 & 2,83 & 26,5 & 0 & 7,07 & 2,26 & 39,51 & 0,00 & 0,09 & 1,49 & 0,05 & 40,04 & 35,0 \\
\hline Out/98 & $12: 10$ & 0,50 & 0,50 & 3,40 & 29,0 & 14 & 8,18 & 4,47 & 89,94 & 0,50 & 0,02 & 0,47 & 0,18 & 103,74 & 8,0 \\
\hline Nov/98 & $15: 30$ & 0,60 & 0,60 & 2,83 & 30,0 & 6 & 7,23 & 2,81 & 55,10 & 0,64 & 0,03 & 1,38 & 0,18 & 75,25 & 8,0 \\
\hline Dez/98 & $13: 05$ & 0,80 & 0,80 & 2,12 & 29,9 & 13 & 8,22 & 3,56 & 72,36 & 0,18 & 0,05 & 0,76 & 0,20 & 118,80 & 4,0 \\
\hline Jan/99 & $12: 35$ & 0,70 & 0,70 & 2,43 & 29,0 & 26 & 7,97 & 3,90 & 83,87 & 0,50 & 0,00 & 0,81 & 0,25 & 26,47 & 4,0 \\
\hline Média & - & 0,54 & 0,50 & 3,74 & 28,91 & 8,0 & 7,66 & 3,28 & 64,51 & 0,58 & 0,04 & 1,14 & 0,12 & 53,57 & 13,43 \\
\hline
\end{tabular}

